\title{
FINANCIAL FRICTIONS AND NEW EXPORTER DYNAMICS
}

\author{
BY DAVID KOHN, FERNANDO LEIBOVICI, AND MICHAL SZKUP
}

Universidad Torcuato Di Tella, Argentina; York University, Canada; University of British

\author{
Columbia, Canada.
}

This paper studies the role of financial frictions as a barrier to international trade. We study new exporter dynamics to identify how these frictions affect export decisions. We introduce a borrowing constraint and working capital requirements into a standard model of international trade, with exports more working capital intensive than domestic sales. Our model can quantitatively account for new exporter dynamics, in contrast to a model with sunk export entry costs. We provide additional evidence in support of our mechanism. We find that financial frictions reduce the impact of a trade liberalization, suggesting that they constitute an important trade barrier.

\section{Introduction}

While tariffs have decreased sharply across developed and emerging economies over recent decades, leading to a huge expansion of international trade, large barriers to international trade remain. Even though non-tariff barriers to international trade are often hard to observe directly in the data, we argue that the dynamics of new exporters are informative of the underlying nature of the frictions affecting firms' export decisions.

1 We thank George Alessandria, David Backus, Gian Luca Clementi, Jonathan Eaton, Mark Gertler, Virgiliu Midrigan, Kim Ruhl, Mike Waugh, Daniel Xu, and seminar participants at Midwest International Trade Meeting 2011, Midwest Macroeconomics Meeting 2011, New York University, Society for Economic Dynamics Meeting 2011, and Pennsylvania State University for helpful comments. We would also like to thank two anonymous referees and the Editor (Harold Cole) for insightful comments that substantially improved the paper. Fernando Leibovici gratefully acknowledges the financial assistance provided by the Social Sciences and Humanities Research Council of Canada (SSHRC) and the C.V. Starr Center for Applied Economics at New York University. Emails: dkohn@utdt.edu, flei@yorku.ca, m.szkup@ubc.ca. Please address correspondence to: Fernando Leibovici, 1034 Vari Hall, 4700 Keele St., Toronto, ON, Canada, M3J 1P3. 
For instance, exports and export intensity are typically increasing in the length of export spells, while the probability that firms stop exporting is decreasing in the number of years that firms have exported. These facts cannot be accounted by models of international trade with sunk export entry costs (Ruhl and Willis, 2014), despite their success in accounting for key cross-sectional facts on exporters and their entry and exit rates Alessandria and Choi, 2014). This suggests it is frictions of a different kind that determine firms' exports.

In this paper, we investigate the extent to which frictions in financial markets distort firms' export decisions, acting as a barrier to international trade, by studying their implications for new exporter dynamics. This approach is motivated by recent studies that document a strong empirical relationship between measures of access to external finance and international trade. Moreover, we are also influenced by the finding that financial frictions can account for salient features of the dynamics of small firms, suggesting that such frictions may also play a key role in driving the dynamics of new exporters, which are typically small. ${ }^{2}$

We begin by documenting salient features of new exporter dynamics and their use of external finance using Chilean plant-level data. On the one hand, we find that new exporters in Chile exhibit the same dynamics documented by previous studies. On the other hand, we observe that external finance plays a key role in the financing of working capital expenditures. Moreover, exporters face relatively higher working capital needs than non-exporters. These findings guide our modeling choices.

We study an economy with heterogeneous firms and idiosyncratic productivity shocks, where firms choose whether to trade internationally. If they choose to export, firms have to pay fixed and variable trade costs. Importantly, we assume that firms' decisions are subject to financial constraints and working capital requirements. In order to produce, firms pay a fraction of their wage bill before revenues are realized, which can be financed using internal or external funds. While firms are free to finance these working capital needs using internal funds, they are required to post collateral in order to obtain external funds. We further assume that working capital requirements are asymmetric: the share of the wage bill that

2 See, for instance, Arellano et al., 2012, Clementi and Hopenhayn, 2006, and Cooley and Quadrini, 2001. 
needs to be paid in advance is higher for foreign sales. ${ }^{3}$

In our model, financial frictions distort export decisions along both the extensive and intensive margins. On the intensive margin, financial frictions force firms with low internal funds, relative to their productivity level, to produce below their optimal scale limiting their output and lowering their total profits. This effect also distorts the extensive margin by reducing the returns from exporting: if a firm chooses to export, it can only earn a fraction of the profits it would earn by operating at their optimal scale. As a result, with financial frictions, productive firms with relatively low assets choose not to export.

We contrast our model with financial frictions with a standard model of export dynamics, in which firms are subject to sunk export entry costs but face no frictions in financial markets. ${ }^{4}$ We separately calibrate both models to match salient features of Chilean plant-level data.

We find that the financial frictions model can account for the dynamics of new exporters observed in the data. In our economy, the majority of new exporters enter the foreign market financially constrained. As they accumulate internal funds, new exporters become less financially constrained and increase their scale rapidly. This raises the return to exporting, making firms less likely to exit the foreign market. Moreover, asymmetric working capital requirements imply an increase in export intensity. As the borrowing constraint is relaxed, exports increase more than domestic sales because foreign sales are relatively more working capital intensive. In contrast, we find that the sunk cost model cannot account for these facts: as firms begin to export, their export exit rate increases, exports decline, and export intensity remains constant. These findings are robust to alternative specifications of the

3 See Section 2 for empirical evidence on asymmetric working capital needs. For alternative finance-related mechanisms that may lead exporters to face higher working capital needs, see Ahn (2011), Amiti and Weinstein (2011), Antras and Foley (2011), and Feenstra et al. (2014).

4 Das et al. (2007) and Alessandria and Choi (2014) find sunk costs to be large and important in accounting for firms' export entry and exit rates, as well as for key cross-sectional facts of firms engaged in international trade. 
sunk model, ${ }^{5}$ and suggest that it is frictions in financial markets, rather than sunk export entry costs, that drive the dynamics of new exporters.

Our model with financial frictions generates hysteresis in export status without sunk costs: a firm that exported in the previous period is more likely to export in the following period since it is likely to have higher assets than one which did not previously export. Therefore, our model can also account for export entry and exit rates, as standard models with sunk costs.

We provide additional evidence in support of our mechanism by studying the performance of our model along other dimensions related to marginal exporters that are not targeted in the calibration strategy. Specifically, we look at the dynamics of domestic sales and external finance upon entry to the export market. We also examine the rate at which firms that recently stopped exporting re-enter the foreign market. We find that our model can account for these additional facts.

Finally, we show that the effects of a trade liberalization crucially depend on whether export entry and exit decisions are assumed to be driven by financing constraints or sunk costs. In particular, we find that the effects of lowering trade barriers on total sales and exports are substantially lower in the model with financial frictions compared to the sunk cost model. In the financial frictions model, firms with low levels of assets are unable to achieve a scale large enough to take advantage of the lower tariffs. As a result, these firms choose not to export and the share of exporters increases by less than in the sunk cost model. We also find that there are indeed large effects from financial development, as relaxing the borrowing constraint leads to a significant increase in exports. These findings suggest that identifying the nature of the underlying trade barriers is important for determining the effects of a trade liberalization and financial development.

The remainder of the paper is organized as follows. In the rest of this section we review the related literature. Section 2 presents empirical evidence on the dynamics of new exporters, and a set of salient facts on the use of external finance and working capital needs. Section 3

\footnotetext{
5 See Section 1 in the online appendix.
} 
presents the model. Section 4 discusses how the model works, and the mechanism through which the model can account for new exporter dynamics. Section 5 presents the quantitative analysis of the model. Section 6 studies the policy implications of our findings. Section 7 concludes.

\subsection{Literature review}

Our work is motivated by recent studies which show that trade models with sunk export entry costs cannot account for the dynamics of new exporters, despite their success along other dimensions. Eaton et al. (2008) and Ruhl and Willis (2014) first documented the different dynamics featured by new and established exporters. In addition, the latter showed that standard models of international trade with sunk costs cannot account for the dynamics of new exporters.

We are also motivated by studies that document a strong empirical relationship between external finance and international trade. Using Italian data, Minetti and Zhu (2011), show that "credit rationed" firms are less likely to export and, to the extent that they do so, are likely to export less. In a similar spirit, Bellone et al. (2010) document a negative relationship between firms' "financial health" and both their export status and export intensity. 6

Our paper is also related to a growing theoretical and quantitative literature that studies the role of financial frictions for trade. Early papers that study the effects of financial constraints on export decisions are Chaney (2013) and Manova (2013), who introduce financial constraints into a standard static Melitz (2003) model. In parallel work, Gross and Verani (2013) also study the role of financial frictions in accounting for new exporter dynamics. In contrast to their work, we calibrate and examine the quantitative implications of our model using plant-level data.

6 See also Manova (2008) and Manova (2013) for evidence on the role of financial frictions and credit market development in explaining the observed sectoral and cross-country patterns of trade. Other papers that document the importance of financial frictions on firms' export decisions are Egger and Kesina (2013), Berman and Hericourt (2010) and Muuls (2008). In contrast, Greenaway et al. (2007) find little evidence on the relevance of financial factors on firms' decision to export. 
The aggregate implications of financial frictions on international trade have been recently studied quantitatively in a trade model by Caggese and Cunat (2013), Brooks and Dovis (2011), and Leibovici (2014). The former two focus on the impact of financial frictions on the gains from trade liberalization, while the latter studies the aggregate implications of financial frictions on international trade.

Alternative explanations have been proposed to account for some of these dynamics. Eaton et al. (2014) point to the role of search frictions to explain the small and increasing export volumes upon entry to foreign markets. They argue that the low but increasing probability of continuing to export arises from initial uncertainty about the idiosyncratic profitability of exporting. Arkolakis (2011) investigates the role of marketing costs and customer capital in explaining increasing export volumes. We present evidence in support of our mechanism, and think of these alternative explanations as complementary to ours.

\section{Empirical evidence}

In this section, we use microdata from Chilean manufacturing plants to document a set of salient features of the dynamics of new exporters and their use of external finance. These facts motivate our subsequent analysis. ${ }^{7}$

\subsection{New exporter dynamics}

Data. We use plant-level data from the Chilean Annual Manufacturing Survey (ENIA), collected by the National Institute of Statistics (INE) for the years 1995 to 2007. The survey collects longitudinal data on all plants with more than ten workers, and provides information on foreign and domestic sales, which constitute our main interest in this subsection.

We exclude observations with negative or missing sales in the domestic or foreign markets, as well as those with zero or missing total sales. We also exclude observations from the following International Standard Industrial Classification (ISIC) Revision 3 categories given

7 While the dynamics of new exporters have been previously documented by Ruhl and Willis (2014) and Eaton et al. (2008) using Colombian data, we show that they also characterize the dynamics of new exporters in Chile. 
their large dependence on natural resource extraction: category 2720 (manufactures of basic precious and non-ferrous metals), and category 2411 (manufactures of basic chemicals, except fertilizers and nitrogen compounds). Our empirical results are robust to the inclusion of these categories.

Figure 1: New exporter dynamics, Chilean data
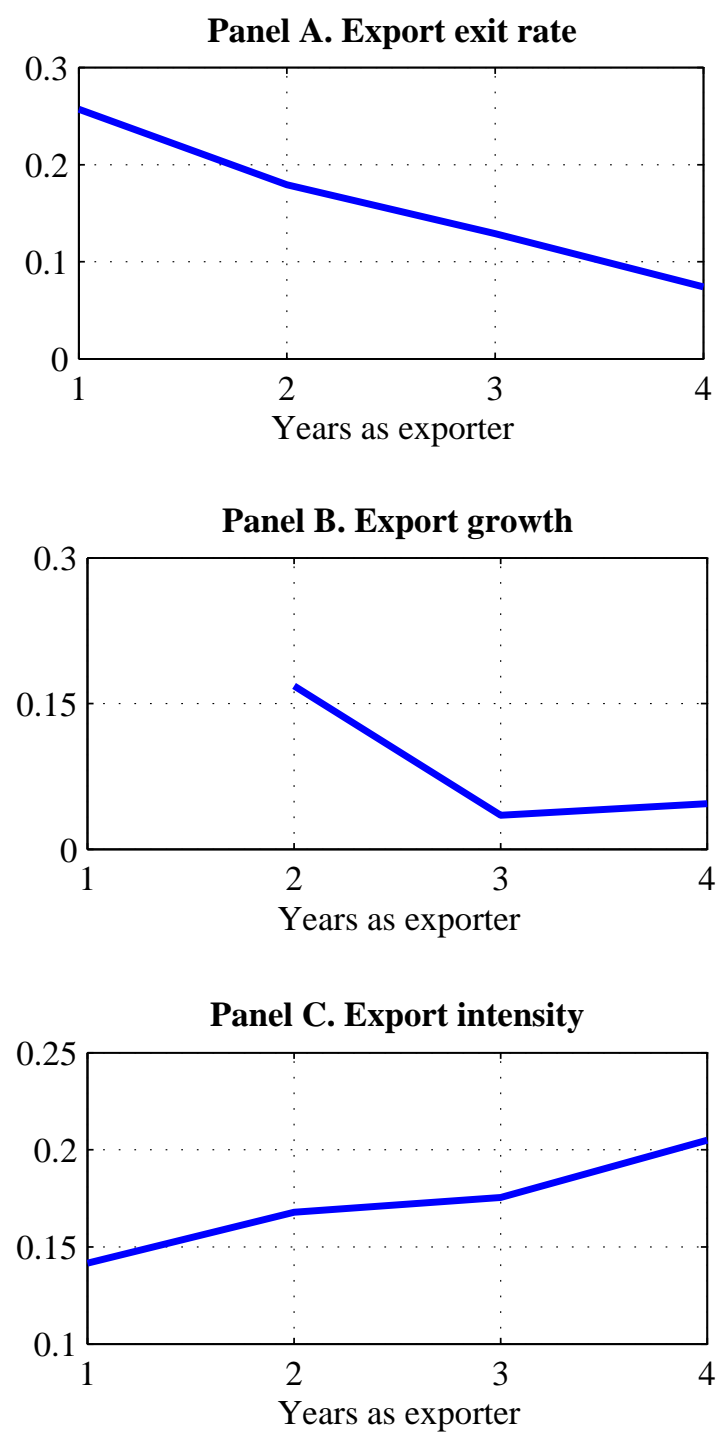

Notes: plant-level data from the Chilean Annual Manufacturing Survey. National Institute of Statistics (INE), 1995 to 2007.

Export exit rate. We begin by documenting that the rate at which exporters stop exporting, but continue to produce domestically, is decreasing in the length of export spells. We compute the export exit rate $Q_{j}$ between export spells of length $j$ and $j+1$ as the share of 
firms that export for $j$ consecutive periods but stop exporting between periods $j$ and $j+1$, while continuing to operate domestically: ${ }^{8} Q_{j}=\frac{\left(N_{j}-\widehat{N}_{j}\right)-N_{j+1}}{N_{j}-\widehat{N}_{j}}$, where $N_{j}$ is the number of firms that exported for $j$ consecutive periods and $\widehat{N}_{j}$ is the number of firms that exit from the survey after exporting for $j$ consecutive periods.

Panel $\mathrm{A}$ in Figure 2 plots the export exit rate as a function of the length of the export spell. While the export exit rate is 25.7 percent upon entry to the foreign market, this rate drops to 7.4 percent for firms that have been exporting for four years.

Exports growth rate. Next, we show that median export sales feature positive growth over the years following entry to the foreign market. ${ }^{9}$ To abstract from the effect of changes in the composition of export cohorts on the exports growth rate due to exit from the foreign market, we restrict attention to firms that continue to export for at least four years.

Panel B in Figure 2 plots the median exports growth rate among this set of plants, where the median is taken across all plant-year observations which exported for the same number of consecutive years. Exports grow over the first 4 years in the export market, though they do so at a decreasing rate, going from 17 percent between the first and second year, to 5 percent between the third and fourth. ${ }^{10}$

Export intensity. Finally, we note that median export intensity, the ratio of exports to total sales, grows consistently over the years following entry to the foreign market. Similarly to the case of export growth, we abstract from the effect of changes in the composition of export cohorts on median export intensity due to exit from the foreign market, by restricting

8 We restrict attention to the set of firms that survive to the following year, and examine the share of these that stop exporting. In this way, we abstract from firms that stop exporting due to exit from the survey, likely because of firms' death. Our results are robust to including these firms in the measured hazard.

9 We report the median to mitigate the potential influence of outliers.

${ }^{10}$ Exports growth rate is adjusted to take into account that in the first year of exporting firms might not export the whole year. Thus, initial exports growth might be over-stated. For more details see the online appendix. 
attention to firms that continue to export for at least four years.

Panel $\mathrm{C}$ in Figure 2 plots the median export intensity among these firms, where the median is taken across all plant-year observations which exported for the same number of consecutive years. Export intensity grows over the first 4 years in the export market, going from 14.2 percent in the first year to 20.5 percent by the fourth year. ${ }^{11}$

\subsection{Working capital and external finance}

We now document salient features of the use of external finance to pay for working capital expenditures by Chilean firms. To do so, we use Chilean firm-level data from the World Bank Enterprise Survey (WBES) ${ }^{12}$ While our main interest is in Chile, we also present the data corresponding to a subset of Latin American countries for comparison. ${ }^{13}$ The results are reported in Table 1. We restrict attention to simple averages across all firms surveyed, averaging over the results from all available waves of the WBES, to avoid biasing our results due to the effects of a particular year.

We observe that external finance plays an important role in the financing of working capital expenditures. First, firms finance a large share (47 percent) of working capital expenditures using external finance. ${ }^{14}$ Second, a large share (49 percent) of external finance loans require firms to post collateral. Third, firms are required to over-collateralize their external finance loans, by posting $\$ 1.55$ of collateral for every $\$ 1$ borrowed. Finally, around a fifth of the firms identify finance "as a major constraint" on the operations of the firm. These patterns fall largely in line with the averages across Latin American countries. These

\footnotetext{
11 As in the case of exports growth, we adjusted the first period export intensity to take into account time-aggregation issues. For more details see the online appendix.

${ }^{12}$ For further description of the data and methodology see Enterprise Surveys (http://www. enterprisesurveys.org), The World Bank.

13 Specifically: Argentina, Brazil, Bolivia, Chile, Colombia, Ecuador, Mexico, Paraguay, Peru, Uruguay and Venezuela.

14 The sum of banks, suppliers' credit and other financing (non-bank financial institutions, and others).
} 
findings guide how we model the financial environment in which firms operate.

Table 1: External finance and working capital expenditures

\begin{tabular}{ccc}
\hline \hline & Chile & Latin America \\
\hline \% of working capital paid using external finance & $47 \%$ & $40 \%$ \\
$\%$ of loans requiring collateral & $49 \%$ & $63 \%$ \\
Collateral per \$ borrowed & $\$ 1.55$ & $\$ 1.73$ \\
\hline Finance "as a major constraint" & $19 \%$ & $25 \%$ \\
\hline \hline
\end{tabular}

Source: World Bank Enterprise Survey, The World Bank.

\subsection{Asymmetric working capital needs}

We now present empirical evidence which suggests that exporters face relatively higher working capital needs than non-exporters. We focus on two variables reported in the World Bank Enterprise Survey: the fraction of total sales paid for after delivery and the inventories of the most important input measured in days of production.

Table 2: Asymmetric working capital needs, Chilean data

\begin{tabular}{ccc}
\hline \hline & $\begin{array}{c}\text { Fraction of total sales } \\
\text { paid for after delivery }\end{array}$ & $\begin{array}{c}\text { Inventory of most important input } \\
\text { (\# of days of production) }\end{array}$ \\
\hline Non-exporters & $57.4 \%$ & 38.7 \\
Exporters & $83.8 \%$ & 55.6 \\
\hline \hline
\end{tabular}

In Table 2 we report sample averages of these variables for Chilean exporters and nonexporters. ${ }^{15}$ We see that there are significant differences between exporters and non-exporters regarding both their payment arrangements and inventory holdings. In our sample 83.8 percent of exporters were paid after delivery while the same was only true for 57.4 percent of non-exporters. Similarly, we find that exporters hold larger inventories of their most impor-

\footnotetext{
15 The differences in the unconditional average of these variables between exporters and non-exporters are statistically significant and robust to controlling for industry fixed effects and total sales. For more details see the online appendix.
} 
tant input than non-exporters. On average, exporters' inventory holdings were sufficient to sustain production for 55.6 days compared to only 38.7 days in the case of non-exporters. Together, these statistics suggest that exporters are more likely to face longer time lags between production and the accrual of revenues, and therefore have higher working capital needs.

As pointed out by Djankov et al. (2010), exporting is also associated with longer delivery lags than domestic sales. Indeed, using World Bank Doing Business dataset, we find that across 196 countries the median time lag between the moment that goods leave the production plant and the time they are loaded on a ship is 18.5 days (in Chile this delay is 15 days). ${ }^{16}$ In addition, Hummels and Schaur (2013) document that the typical good imported to the US spends 20 days on a vessel, and Leibovici and Waugh (2014) estimate that the average total time it takes to import a good into the US increases to 33 days once the data from the World Bank Doing Business dataset is taken into account. These long delivery lags associated with exporting further suggest that exporters have higher working capital needs than non-exporters.

Motivated by this evidence, throughout the rest of the paper we assume that exporting is associated with higher working capital needs than domestic sales.

\section{Model}

In this section we present a model with fixed and sunk costs of exporting, as well as financial constraints. This model nests the two frameworks that we compare in the quantitative section.

We study an economy populated by a continuum of monopolistically competitive firms, each producing a differentiated good and owned by an entrepreneur. Entrepreneurs are risk-averse, with preferences represented by a constant relative risk aversion utility function, and decide how much to consume and save. They have access to a one-period asset for saving purposes, which pays a constant return $r$, given exogenously. We also assume for

\footnotetext{
16 The details regarding this dataset can be found at http://www.doingbusiness.org.
} 
simplicity that intra-period loans bear zero interest rate. In what follows, we refer to firms and entrepreneurs interchangeably.

Firms choose how much to produce in the domestic market and whether to enter the export market. If they export, they also choose the volume of foreign sales. We assume that the real wage, the interest rate and the demand schedules faced by firms in each market are all exogenously given.

To start exporting, firms have to pay both a sunk cost $S$ and a fixed cost of exporting $F$, while firms that exported in the previous period pay only the latter. Both costs are measured in units of labor. Furthermore, exporting firms face iceberg $\operatorname{costs} \tau$, as is standard in the literature.

Firm $i$ produces according to a constant returns to scale production technology, $y_{i}=$ $z_{i} N_{i}, i \in[0,1]$, where $N_{i}$ is the total labor input and $z_{i}$ is firm $i$ 's idiosyncratic productivity. We assume that $\ln z_{i}$ follows a time invariant $A R(1)$ process

$$
\ln z_{i, t}=(1-\rho) \mu+\rho \ln z_{i, t-1}+\varepsilon_{i, t}, \quad \varepsilon_{i, t} \sim N\left(0, \sigma_{\varepsilon}^{2}\right)
$$

Firms face exogenous domestic and foreign constant elasticity of substitution (CES) demand schedules:

$$
q_{i}=\left(\frac{p_{i}}{P}\right)^{-\sigma} Q, \quad q_{i}^{*}=\left(\frac{p_{i}^{*}}{P^{*}}\right)^{-\sigma} Q^{*}
$$

where $p_{i}$ is the price charged by firm $i$ in the domestic market, $P$ is the aggregate price level in the home country, and $Q$ is aggregate demand in the domestic market; $p_{i}^{*}, P^{*}$ and $Q^{*}$ are the corresponding prices and quantities in the foreign market. Finally, $\sigma$ is the elasticity of substitution between any two goods in the domestic and foreign markets.

We assume that firms face financial constraints in the form of working capital requirements and borrowing constraints. More precisely, firms have to pay a fraction $\alpha \in[0,1]$ of the wage bill for domestic sales at the beginning of each period, before production takes place and revenues are realized. Instead, if they export they need to pay in advance the full amount of the production costs for the export market, and the costs associated with 
exporting: the fixed cost and, in the case of firms that start exporting this period, the sunk cost. ${ }^{17}$ However, due to imperfections in the financial market, we assume that firms can only borrow up to a multiple $\lambda-1 \geq 0$ of their assets. ${ }^{18}$ It follows that the financial constraint faced by the firm can be expressed as

$$
\alpha w n+e^{\prime}\left[w F+(1-e) w S+w n^{*}\right] \leq \lambda a
$$

where $a$ are pledgeable assets that the firm owns, $\alpha$ is the fraction of the wage bill for domestic sales that has to be paid in advance, $n$ and $n^{*}$ are the amount of labor hired for domestic and foreign sales, respectively, $e$ is an indicator variable that takes value 0 if the firm produced only for the domestic market in the previous period and 1 if it exported, and $e^{\prime}$ is an indicator variable that takes value 0 if the firm sells only domestically and 1 if the firm chooses to export in the current period. If the firm exported in the previous period $(e=1)$, it has to pay $F$ in order to export, otherwise it has to pay $F+S$. In what follows, we refer to $e$ as the firm's past export status while $e^{\prime}$ is the firm's current export status.

Figure 3 presents the timeline of events within a period. At the beginning of a period, firms choose simultaneously whether to export or not and how much to produce for each market. Given their asset holdings, firms take a loan that is used to pay for production and export costs. Once the costs are paid, production takes place and firms send their goods to the destination markets. At the end of the period firms receive revenues from the sales and repay their debt. Afterwards, entrepreneurs decide how much to consume and save determining the level of assets available in the next period.

We now describe in detail the firms' static problem and the dynamic problem of entrepreneurs.

\footnotetext{
17 The asymmetry across markets in the borrowing constraint is meant to capture the different financing requirements of the export and domestic markets, as documented in the previous section. If we set $\alpha=0$ then the resulting borrowing constraint is similar to the one in Manova $(2013)$.

18 This type of borrowing constraint would arise, for example, in an economy where lenders and borrowers were restricted to one-period contracts only, and the borrower could run away with a fraction of his assets.
} 
Figure 2: New exporter dynamics, Chilean data
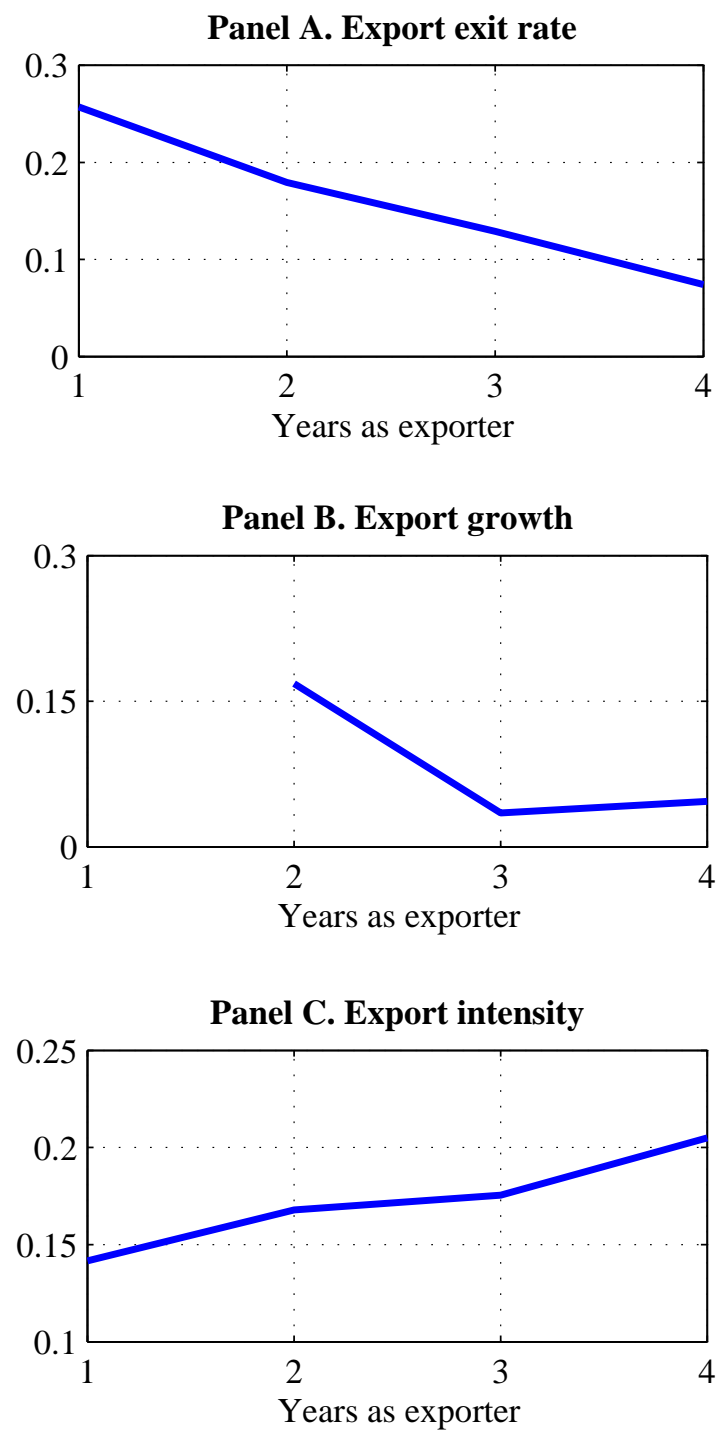

Notes: plant-level data from the Chilean Annual Manufacturing Survey. National Institute of Statistics (INE), 1995 to 2007.

\subsection{Static problem}

Each period, every firm $i$ maximizes static profits from sales in the domestic and foreign markets, if it chooses to export. Note that due to the constant returns to scale technology, we can separate firms' production into domestic and foreign sales. However, given the constraint on assets, the quantities exported and sold domestically are jointly determined.

The static problem of a firm with productivity $z$, assets $a$, past export status $e$, and 
Figure 3: Timeline

Choose $e^{\prime}, q$ and $q^{*}$

Take loan

Pay for production

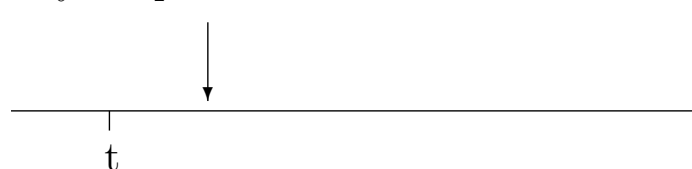

Revenues are realized

Debt is paid

current export status $e^{\prime}$, is given by:

$$
\begin{aligned}
& \pi\left(a, z, e, e^{\prime}\right)=\max _{n, n^{*}, q, q^{*}} p q-w n+e^{\prime}\left[p^{*} q^{*}-w n^{*}-w F-(1-e) w S\right] \\
& \text { s.t. } \\
& n=\frac{q}{z}, \quad n^{*}=\frac{\tau q^{*}}{z} \\
& \\
& q=\left(\frac{p}{P}\right)^{-\sigma} Q, \quad q^{*}=\left(\frac{p^{*}}{P^{*}}\right)^{-\sigma} Q^{*} \\
& \alpha w n+e^{\prime}\left[w F+(1-e) w S+w n^{*}\right] \leq \lambda a
\end{aligned}
$$

\subsection{Dynamic problem}

We now describe the dynamic problem faced by the entrepreneur. Let $v(a, z, e)$ be the value function of a firm with assets $a$, productivity $z$, and previous export status $e$, that chooses whether to export or not, and how much to save. ${ }^{19}$ The value function for the

19 The aggregate state variables are $P, Q, P^{*}$ and $Q^{*}$; the aggregate price levels and aggregate demands at home and abroad. To simplify the notation we omit the aggregate state variables when writing the dynamic problem. 
entrepreneur is given by:

$$
\begin{aligned}
v(a, z, e) & =\max _{c, a^{\prime}, e^{\prime}}\left\{\frac{c^{1-\gamma}}{1-\gamma}+\beta E\left[v\left(a^{\prime}, z^{\prime}, e^{\prime}\right)\right]\right\} \\
\text { s.t. } \quad c+\frac{a^{\prime}}{1+r} & =a+\pi\left(a, z, e, e^{\prime}\right) \\
a^{\prime} & \geq 0
\end{aligned}
$$

where the expectation is taken over the future values of productivity shocks. Note that the only difference between the problem of a continuing exporter and a potential starter is the fact that the former doesn't have to pay a sunk cost $w S$ (included in $\pi\left(a, z, e, e^{\prime}\right)$ ), if it decides to export this period. Therefore, in the absence of the sunk cost the two problems are the same and the past export status is irrelevant for the decisions in the current period.

The Euler equation associated with the dynamic problem is given by

$$
\beta(1+r) E\left[\left(1+\pi_{a}\left(a^{\prime}, z^{\prime}, e^{\prime}, e^{\prime \prime}\right)\right)\left(\frac{c^{\prime}}{c}\right)^{-\gamma}\right]=1
$$

where $\pi_{a}$ is the partial derivative of the profit function with respect to assets, $\pi_{a}\left(a^{\prime}, z^{\prime}, e^{\prime}, e^{\prime \prime}\right)=$ 0 if the firm is unconstrained tomorrow, and $\pi_{a}\left(a^{\prime}, z^{\prime}, e^{\prime}, e^{\prime \prime}\right)>0$ if the firm is constrained. Note that each entrepreneur faces a positive probability of a large productivity shock, $z^{\prime}$, such that his assets will be insufficient to finance his optimal production. This implies that all entrepreneurs face a higher effective return from savings than they would in the frictionless economy. Moreover, the poorer is the entrepreneur, the higher the probability that he receives a productivity shock that will make him constrained tomorrow. Since $\pi_{a}\left(a^{\prime}, z^{\prime}, e^{\prime}, e^{\prime \prime}\right)$ is a decreasing function of assets, this means that the firms with low levels of assets are the ones that have the highest effective rates of return and, thus, the highest saving rates.

\section{Mechanism}

Above we described a model with both sunk costs and borrowing constraints. The model nests the two setups that we compare quantitatively in Section 5: (1) a model without sunk costs but with borrowing constraints; (2) a model with sunk costs but without borrowing 
constraints. $^{20}$ The sunk cost model has been previously studied in detail, therefore we focus on the financial frictions model. In particular, we explain how financial frictions allow us to capture qualitatively the stylized facts of new exporter dynamics. ${ }^{21}$

We start by briefly discussing a model without sunk costs and without financial constraints, as a benchmark. We then introduce the borrowing constraint described above, but we keep the assumption of no sunk costs. As we show below, financial frictions induce hysteresis in export decisions, allowing us to capture some of the cross-sectional features of the data that commonly require the presence of sunk costs in standard models.

\subsection{Frictionless model}

In the absence of financial frictions and sunk costs, the only state variable in the firm's problem is its productivity level. In this case, the static problem can be written as:

$$
\pi(z)=\max _{n, n^{*}, e^{\prime} \in\{0,1\}}(n z)^{\frac{\sigma-1}{\sigma}} P Q^{1 / \sigma}-w n+e^{\prime}\left[\left(\frac{n^{*} z}{\tau}\right)^{\frac{\sigma-1}{\sigma}} P^{*}\left(Q^{*}\right)^{1 / \sigma}-w n^{*}-w F\right]
$$

The solution to this problem yields a threshold level of productivity $\bar{z}$ such that if the firm's productivity is higher than this threshold, the firm exports. Otherwise, the firm produces only for the domestic market. Note that the choices of domestic and foreign sales are independent of each other and, therefore, a firm will export if and only if $\hat{p}^{*} \hat{q}^{*}-w \hat{n}^{*} \geq w F$, where the variables with "hats" are the solution to the problem above.

Firms that choose to export, upon entry to the foreign market adjust their export volume to its optimal level which is then driven only by movements in productivity. Moreover, export intensity stays constant throughout their export spells. The following proposition presents the solution to the above problem.

Proposition 1. The solution to the firm's static problem in the frictionless economy is given

\footnotetext{
20 The model still features incomplete markets and a non-negativity constraint on asset-holdings.

21 Note that the analysis in this section is for changes in decision rules given fixed prices, not general equilibrium effects, which are absent in the model.
} 
by optimal labor demand schedules for domestic and foreign production, $\hat{n}$ and $\hat{n}^{*}$ respectively, and a constant threshold level of productivity $z=\bar{z}$, such that a firm exports if its productivity is above $\bar{z}$, and produces only domestically otherwise, where

1. $\hat{n}$ and $\hat{n}^{*}$ are given by

$$
\hat{n}=\left[\left(\frac{\sigma}{\sigma-1}\right) \frac{w}{P Q^{1 / \sigma}}\right]^{-\sigma} z^{\sigma-1}, \quad \hat{n}^{*}=\left[\left(\frac{\sigma}{\sigma-1}\right) \frac{w}{P^{*}\left(Q^{*}\right)^{1 / \sigma}}\right]^{-\sigma} \tau^{1-\sigma} z^{\sigma-1}
$$

2. $z=\bar{z}$ is given by

$$
\bar{z}=\frac{1}{\sigma-1}\left[\sigma \frac{w}{P^{*}\left(Q^{*}\right)^{1 / \sigma}}\right]^{\frac{\sigma}{\sigma-1}} \tau F^{\frac{1}{\sigma-1}}
$$

3. Optimal sales in the domestic and foreign markets are, $\hat{p} \hat{q}=(z \hat{n})^{\frac{\sigma-1}{\sigma}} Q^{\frac{1}{\sigma}} P$ and $\hat{p}^{*} \hat{q}^{*}=$ $\left(\frac{z}{\tau} \hat{n}^{*}\right)^{\frac{\sigma-1}{\sigma}} Q^{* \frac{1}{\sigma}} P^{*}$, respectively. Export intensity is constant, and it is given by:

$$
\frac{\hat{p}^{*} \hat{q}^{*}}{\hat{p} \hat{q}+\hat{p}^{*} \hat{q}^{*}}=\frac{\frac{P^{* \sigma} Q^{*}}{\tau^{\sigma-1}}}{P^{\sigma} Q+\frac{P^{* \sigma} Q^{*}}{\tau^{\sigma-1}}}
$$

if the firm exports, and is 0 otherwise.

Proof. See Appendix A.1.

\subsection{Financial frictions model}

While in the frictionless economy described above asset holdings do not affect firms' decisions, in the presence of a borrowing constraint they become a state variable of the firm's problem. This is because working capital needs faced by the firm have to be paid for before production takes place, while the funds available to a firm are limited to a multiple $\lambda$ of its assets. In this case the static problem can be written as:

$$
\begin{gathered}
\pi(z, a)=\max _{n, n^{*}, e^{\prime} \in\{0,1\}}(n z)^{\frac{\sigma-1}{\sigma}} P Q^{1 / \sigma}-w n+e^{\prime}\left[\left(\frac{n^{*} z}{\tau}\right)^{\frac{\sigma-1}{\sigma}} P^{*}\left(Q^{*}\right)^{1 / \sigma}-w n^{*}-w F\right] \\
\text { s.t. } \alpha w n+e^{\prime}\left[w F+w n^{*}\right] \leq \lambda a
\end{gathered}
$$


The borrowing constraint has important consequences on the firms' static maximization problem. First of all, abstracting from export entry and exit decisions, it affects the intensive margin by potentially reducing firms' production scale. Firms with low levels of assets, with a binding borrowing constraint, are forced to produce below their optimal scale. In response to a positive productivity shock, these firms expand their production gradually as they accumulate assets.

The borrowing constraint also implies that the optimal quantities produced by firms in the domestic and export markets become interdependent: if the constraint is binding, the more a firm produces in one market, the less it can produce in the other. Therefore, there is now an extra cost of exporting: the opportunity cost of the assets used to export. Since foreign and domestic sales are linked, a firm exports if and only if

$$
\pi_{F}(e=1, a-w F)+\pi_{D}(e=1, a-w F)-w F \geq \pi_{D}(e=0, a)
$$

where $\pi_{j}(e=i, \tilde{a})$ denotes profits from sales to market $j$, where $j \in\{D, F\}$, and $\tilde{a}$ are the assets left after paying for the fixed cost of exporting. ${ }^{22}$

Equation 1 implies that a firm becomes an exporter if the total profits of exporting are greater than the profits it can earn by producing only domestically. Now it is no longer true that there is a constant threshold level of productivity above which firms will export. Instead, as shown below, this threshold level depends on asset holdings, $a$. Thus, the financial constraint also affects the extensive margin of a firm's export decisions.

To understand better the firm's decision to export, consider the following decomposition

\footnotetext{
${ }^{22}$ For a firm selling only domestically, $\tilde{a}=a$, while for the exporter $\tilde{a}=a-w F$.
} 
of Equation 1:

$$
\begin{gathered}
\pi_{F}(e=1, a-w F)+\pi_{D}(e=1, a-w F)-w F-\pi_{D}(e=0, a)= \\
\underbrace{\left(\pi_{F}(e=1, a-w F)+\pi_{D}(e=1, a-w F)-\pi_{D}(e=0, a-w F)\right)}_{\text {Diversification Gain }} \\
-\underbrace{\left(\pi_{D}(e=0, a)-\pi_{D}(e=0, a-w F)\right)}_{\text {Opportunity Cost }}-w F
\end{gathered}
$$

The first term of the above decomposition is a "diversification gain" from selling for two markets instead of selling just in one market, and it is always positive. ${ }^{23}$ This gain arises because each firm faces downward sloping demand curves in both markets and hence, given a constant amount of assets, it is always profitable to split sales between these two markets. The second term is the "opportunity cost" of exporting: some assets, previously used to finance domestic production, need to be used to pay for the fixed and production costs of exporting. This cost diminishes as firms accumulate assets. Finally, as in the frictionless economy, there is a fixed cost of exporting $w F$. Therefore, a firm compares the "diversification gain" against the fixed cost and the "opportunity cost", and decides to export if the gains outweigh the costs.

Given the considerations above, we now describe the optimal choices of the firm in the setup with financial frictions. For ease of exposition, we first analyze the case with symmetric working capital needs $(\alpha=1)$. We then discuss the problem when $\alpha<1$, which we further analyze in the quantitative section.

Symmetric working capital needs $(\boldsymbol{\alpha}=\mathbf{1})$. In the case when $\alpha=1$, we can obtain a closed-form solution to the firm's static problem. Figure 4 shows the combinations of $(z, a)$ for which firms choose to export, and whether firms are constrained or unconstrained.

The state space can be divided into four different regions: Region 1 ("R1"), where firms produce only for the domestic market and operate at the optimal scale; Region 2 ("R2"), where firms produce only domestically and are constrained; Region 3 ("R3"), where

\footnotetext{
${ }^{23}$ Whenever a firm has enough assets to cover the fixed cost.
} 
Figure 4: Decision rules, $\alpha=1$

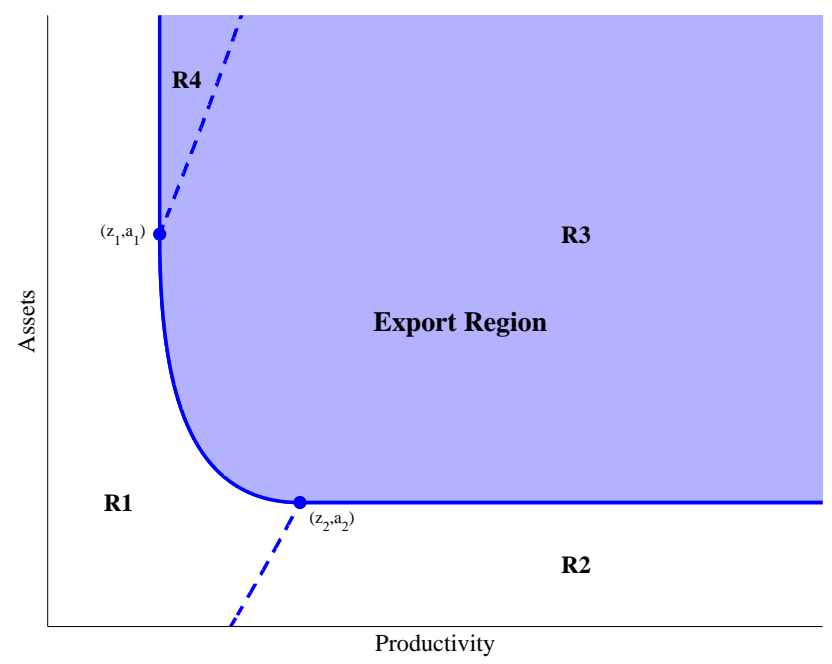

firms decide to export and are constrained; and Region 4 ("R4"), where firms produce the unconstrained optimal quantities for both markets.

The decision to export is now a function of both assets and productivity. While it is still true that there is a productivity threshold, this threshold is now a function of assets and can be divided into three segments: (i) For assets greater than $a_{1}$, the export decision is independent of asset holdings, and the threshold is $\bar{z}(a)=\bar{z}$, the same as in the frictionless economy; (ii) for assets below $a_{1}$ and above $a_{2}$, the export decision depends on both assets and productivity, and $\bar{z}(a)$ is a decreasing function of assets; (iii) for asset holdings lower than $a_{1}$ the firm never chooses to export, and $\bar{z}(a)=\infty$. Note also that for productivity greater than $z_{2}$ the export decision is independent of $z$ and depends only on asset holdings: a firm with productivity $z \geq z_{2}$ exports if and only if its level of assets is greater than $a_{2}$.

The shape of the export threshold can be better understood using the decomposition of gains from exporting described above in Equation 2. First note that, given asset holdings, the opportunity cost of exporting is increasing in productivity because more productive firms can use these assets to produce relatively more. On the other hand, the larger scale of production enjoyed by more productive firms allows them to obtain higher "diversification gains". For productivity $z_{1}<z<z_{2}$, the second effect dominates, while for $z \geq z_{2}$, under symmetric capital requirements $(\alpha=1)$, these two effects exactly compensate each other, so 
that the decision to export becomes independent of the productivity.

Given the level of productivity, the "opportunity cost" is decreasing in the level of assets, because of decreasing marginal profits in the domestic market: when firms produce large quantities, they have low marginal profits for each extra unit produced using these assets resulting in low "opportunity cost". Moreover, a higher level of assets implies a larger "diversification gain" since firms with high asset holdings can produce at a larger scale. Both effects make firms with higher assets more likely to become exporters.

Asymmetric working capital needs $(\alpha<1)$. Consider now the case where the working capital needs are higher for exports than for domestic sales. Specifically, we assume that only a fraction $\alpha$ of the production costs for the domestic market needs to be paid in advance, while in the case of exports the full amount of labor costs is paid before production. Figure 5 shows the export threshold and the different regions for this case. For comparison we also plot the export threshold for the case of symmetric working capital requirements, $\alpha=1$ (the dashed-dotted line).

Figure 5: Decision rules, $\alpha<1$

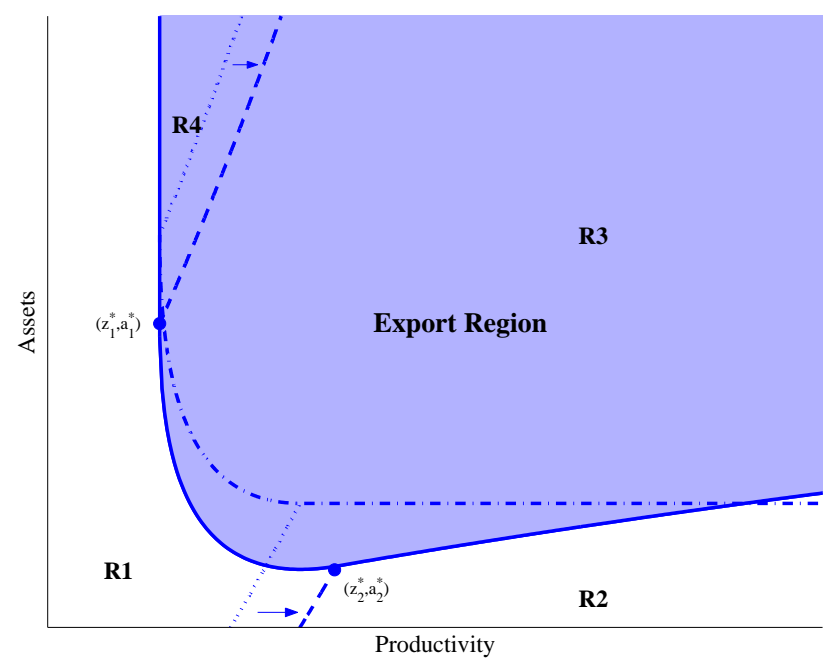

Notes: the solid line is the export threshold. The dashed lines are the constrained/unconstrained thresholds. The dashed-dotted line is the export threshold for the case $\alpha=1$.

There are several differences with respect to the case $\alpha=1$. First, conditional on the export status, some firms that were constrained before, are now unconstrained: with lower 
$\alpha$ firms need less assets to become unconstrained. This is reflected in Figure 5 by the fact that the dashed line between regions R3 and R4 is shifted to the right relative to Figure 4 , implying that the segment of the export threshold that is independent of the level of assets is now larger; $a_{1}^{*}<a_{1}$. Furthermore, the dashed line between regions R1 and R2 is also shifted to the right, implying that the firms that produce only for the domestic market become constrained for a higher level of productivity. This is because, all else equal, now firms require less assets to produce domestically.

This is not the only change. As can be seen in Figure 5, for low levels of productivity there are firms for which it was optimal not to export at a given $(z, a)$ and now, with lower $\alpha$ choose to export. As productivity increases, the threshold level of assets above which firms find it optimal to export, $a(z)$, also increases. At one point this threshold intersects the one for the case $\alpha=1$, meaning that for high productivity levels there are combinations of $(z, a)$ at which it was optimal to export before but not any more. Below we explain the intuition behind this result.

First, a lower $\alpha$ makes production for domestic market less "asset-intensive" and hence allows firms to increase their total production compared to the case with $\alpha=1$. On the other hand, a lower $\alpha$ makes exporting relatively more costly (in terms of assets) compared to domestic production. The first effect increases the diversification gains: a larger production scale means lower marginal profits at home and hence stronger incentives to export. The second effect decreases the diversification gains: it is relatively costlier, in terms of assets, to produce for the foreign market, discouraging exporting. Furthermore, the "opportunity cost" of exporting is now lower than before, for any given level of assets and productivity. This is because a lower $\alpha$ is akin to a larger level of assets, and the opportunity cost is decreasing in assets, as explained above.

For low productivity levels, the lower opportunity cost and the effect of an increase in total production dominate the effect of a higher relative cost of exports. This is why a firm with a relatively low level of assets and productivity that chose to produce only domestically with $\alpha=1$, now decides to export. For high levels of productivity the opposite is true and it 
is the effect of higher relative cost of exports that dominates, resulting in the positive slope of the threshold. At one point this effect becomes so strong that some of the firms that would export with $\alpha=1$ decide to produce only for the domestic market.

\subsection{New exporter dynamics}

Having described the consequences of the borrowing constraint on firms' production scale and decision to export, we now explain how the model can qualitatively match the stylized facts of new exporter dynamics reported in Section 2 .

The key feature of the model that allows us to capture these dynamics is the gradual accumulation of assets by new exporters. For this mechanism to influence firms' decisions, most of the new exporters need to be financially constrained. Therefore, in what follows we restrict our attention to firms that begin exporting in region $\mathrm{R} 3$, that is, financially constrained exporters. For these firms the Lagrange multiplier $\mu$ on the working capital constraint is positive. In our setup, this multiplier captures the increase in profits due to an additional unit of assets. The following proposition describes export sales and export intensity for a constrained exporter.

Proposition 2. Consider a constrained exporter $(\mu>0)$. Then:

1. Export sales are given by

$$
p^{*} q^{*}=P^{* \sigma} Q^{*}\left[\frac{w \tau(1+\mu)}{z} \frac{\sigma}{\sigma-1}\right]^{1-\sigma}
$$

2. Export intensity is given by

$$
\frac{p^{*} q^{*}}{p q+p^{*} q^{*}}=\frac{P^{* \sigma} Q^{*}[\tau(1+\mu)]^{1-\sigma}}{P^{\sigma} Q[(1+\alpha \mu)]^{1-\sigma}+P^{* \sigma} Q^{*}[\tau(1+\mu)]^{1-\sigma}}
$$

3. Export sales, $p^{*} q^{*}$, and export intensity, $\frac{p^{*} q^{*}}{p q+p^{*} q^{*}}$, increase as firms accumulate assets and become less constrained, that is, as $\mu$ decreases.

Proof. See Appendix A.1. 
Financially constrained firms are unable to produce at their optimal scale. However, conditional on staying in the export market, they accumulate assets and relax their borrowing constraint (decreasing the Lagrange multiplier $\mu$ ). By the above proposition, this leads them to expand their production and foreign sales. To the extent that sufficiently many new exporters are financially constrained, this allows us to capture the increasing volume of exports among new exporters.

With asymmetric working capital needs $(\alpha<1)$, exporting is relatively more costly for financially constrained firms. Therefore, firms with low assets choose a low export intensity upon entry to the foreign market. As exporting firms accumulate assets, they choose to sell more in the market that is relatively more working capital intensive. This is because the opportunity cost of exporting is decreasing in asset holdings, while the gains from diversifying its output across both markets are increasing. Therefore export intensity increases as the firm continues to export.

Furthermore, our model can generate a decreasing export exit rate as cohorts of new exporters age. The intuition for this result comes from the fact that the interval of productivity values for which a firm optimally exports is increasing in the level of asset holdings. When a firm with relatively low assets and a productivity level close to the threshold begins to export, the range of productivity shocks for which it continues producing for the foreign market is relatively small. However, conditional on continuing to export, the firm accumulates funds and moves away from that threshold increasing the range of productivity values for which they decide to export. This, in turn, decreases the probability of receiving productivity shocks that make exporting unprofitable. Hence, the implied hazard rate for a cohort of new exporters is decreasing.

Our model with financial frictions generates hysteresis in export status without sunk costs: a firm that exported in the previous period is more likely to export in the following period since it is likely to have higher assets than one which did not previously export. Intuitively, financial frictions act as sunk costs in our model, since the magnitude of the fixed export cost relative to profits is decreasing in the length of the export spells, as firms 
accumulate assets and increase their scale. Therefore, our model may potentially account for some of the facts accounted by standard models with sunk costs, such as export entry and exit rates.

\section{Quantitative analysis}

In this section we study the quantitative implications of our model. To compare our model's implications with the data, we first extend the model to allow for heterogeneous export entry costs. ${ }^{24}$ We then calibrate the model to match key cross-sectional moments, and examine the extent to which it can account for the dynamics of new exporters observed in the data. We compare these results with those of a standard model used in the literature, one with sunk export entry costs and no financial frictions. ${ }^{25}$ Furthermore, we study the implications of our model for the dynamics of domestic sales and external finance upon entry to the export market, as well as for rate at which firms that just stopped exporting re-enter the foreign market.

Heterogeneous fixed costs. In the previous section we presented the model and explained the underlying mechanism through which it can match the dynamics of new exporters. We introduce a small share of firms, $\eta$, that face only a fraction, $\kappa<1$, of the fixed and sunk

costs, $F$ and $S$, if they decide to export. As we explain below, these firms are needed to match the firms' size distribution by export status, ranked by total sales. All the derivations above remain unchanged, except that we now replace $F$ and $S$ by:

$$
\left\{F_{i}, S_{i}\right\}= \begin{cases}\{F, S\} & \text { if } i=H \\ \{\kappa F, \kappa S\} & \text { if } i=L\end{cases}
$$

24 This extension is only needed for quantitative reasons, and it does not affect any of the conclusions of the paper. See Section 3 of the online appendix for the quantitative results from a model with homogeneous export entry costs.

${ }^{25}$ In Section 1 of the online appendix we study the sensitivity of our quantitative results to alternative specifications of the sunk cost model. 
where $\kappa<1$, and there is a share $(1-\eta)<1$ of firms of type $H$ and a share $\eta<1$ of firms of type $L$.

While our conclusions remain valid without heterogeneous export entry costs, these are a standard feature of quantitative models of international trade with heterogeneous firms. ${ }^{26}$ Moreover, this assumption can capture the existence of two types of firms, as in Bai et al. (2013): some that export directly (type $H$ above), and others that do it through intermediaries and face lower fixed and sunk costs of exporting (type $L$ above). ${ }^{27}$

\subsection{Calibration}

In this subsection, we discuss our approach for calibrating the financial frictions and sunk cost models. We study the partial equilibrium of this economy, setting $w$ equal to 1 and $r$ equal to $0.01 .^{28}$ We divide the remaining parameters into two groups. The first group is predetermined, while the second is calibrated to match key moments of the data, taking different values for each of the two models. Note that we do not target the dynamics of new exporters documented in Section 2.

The first group of parameters consists of $\gamma, \sigma$, and $\lambda$ (in the financial frictions model only). We set the risk aversion parameter, $\gamma$ equal to 2 , which implies an intertemporal elasticity of substitution $1 / \gamma$ equal to 0.5 , and the elasticity of substitution across varieties, $\sigma$, equal to 5 . These values fall within the ranges of values that have been used in previous studies. ${ }^{29}$ We set $\lambda$ in the financial frictions model to match the amount of collateral posted per dollar borrowed that we observe in the data. We measure the amount of collateral posted per dollar borrowed, needed to calibrate $\lambda$ in the financial frictions model, using Chilean data for years 2006 and 2010 from the World Bank Enterprise Survey.

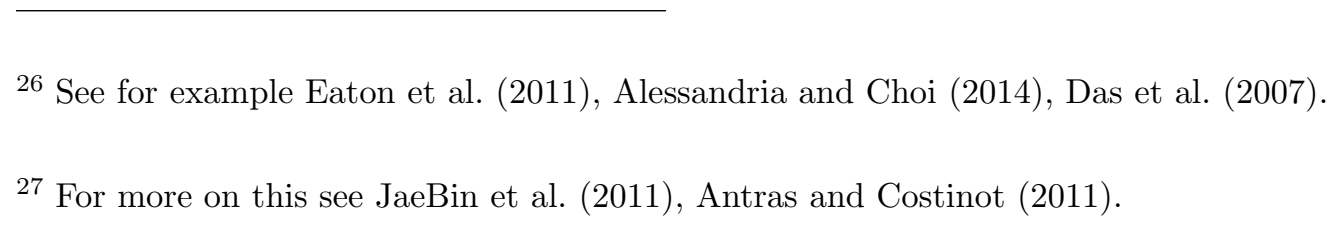

${ }^{28}$ We assume that domestic and export markets are symmetric and normalize $P$ and $P^{*}$ equal to $1, Q$ and $Q^{*}$ to 50 .

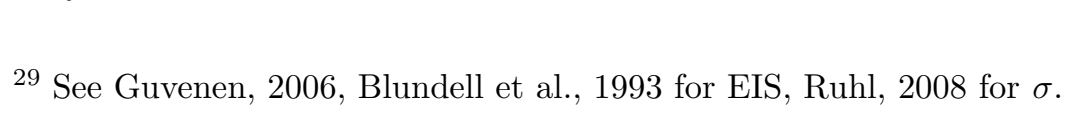


Table 3: Parameterization

\begin{tabular}{|c|c|c|}
\hline & Financial frictions & Sunk costs \\
\hline & \multicolumn{2}{|c|}{ Predetermined } \\
\hline$\gamma$ & 2 & 2 \\
\hline$\sigma$ & 5 & 5 \\
\hline \multirow[t]{2}{*}{$\lambda$} & 1.64 & - \\
\hline & \multicolumn{2}{|c|}{ Calibrated } \\
\hline$\beta$ & 0.83 & 0.98 \\
\hline$F$ & 1.70 & 1.03 \\
\hline$S$ & - & 4.14 \\
\hline$\eta$ & 0.16 & 0.05 \\
\hline$\kappa$ & 0.11 & 0.23 \\
\hline$\tau$ & 1.51 & 1.52 \\
\hline$\rho$ & 0.91 & 0.78 \\
\hline$\sigma_{\varepsilon}$ & 0.11 & 0.18 \\
\hline$\alpha$ & 0.53 & - \\
\hline
\end{tabular}

In the model with financial frictions, the second group of parameters consists of $\beta, \tau, \sigma_{\varepsilon}$, $\rho, F, \eta, \kappa$, and $\alpha$. We choose them to match the following moments: $(i)$ export entry rate, (ii) export exit rate, (iii) median export intensity, (iv) median exporter size premium, ${ }^{30}$ and $(v)$ total external finance to sales ratio. ${ }^{31}$ We also target moments of the size distribution of exporters. We first rank all firms by size, according to total sales, and target the share of exporters (among all exporters) with sales: (vi) below the $25^{\text {th }}$ percentile across all firms $\left(\Phi_{(0,25)}^{X}\right)$, (vii) between the $50^{\text {th }}$ and $75^{\text {th }}$ percentile $\left(\Phi^{X_{(50,75)}}\right)$, and $(v i i i)$ above the $75^{\text {th }}$ percentile $\left(\Phi_{(75,100)}^{X}\right)$. These moments are sufficient to characterize the distribution of exporters and non-exporters across the four quartiles ranked by total sales.

In the sunk cost model we match $S$ instead of $\alpha$. For this model we set $\alpha$, the fraction paid in advance of the labor used for foreign sales, to the value calibrated in the financial

\footnotetext{
${ }^{30}$ Median number of workers employed by exporters relative to non-exporters.

${ }^{31}$ We compute external finance as $\max \left\{\alpha w n+e^{\prime}\left[w F+(1-e) w S+w n^{*}\right]-a, 0\right\}$, for each firm.
} 
frictions model. ${ }^{32}$

We compute the target moments $(i)$ to $(i v)$ and $(v i)$ to (viii) from the Chilean panel dataset discussed in Section 2. For (v), we obtain the total external finance from Superintendencia de Bancos e Instituciones Financieras de Chile, ${ }^{33}$ and sales from Chilean plant-level data.

Table 4: Target moments

\begin{tabular}{cccc}
\hline \hline & Data & Financial frictions & Sunk costs \\
\hline Export entry rate & 0.03 & 0.03 & 0.03 \\
Export exit rate & 0.11 & 0.11 & 0.11 \\
Median exports/sales & 0.16 & 0.16 & 0.16 \\
Median exporter size premium & 4.81 & 4.76 & 4.86 \\
External finance/sales & 0.12 & 0.12 & 0.12 \\
& \multicolumn{2}{c}{ Size distribution of exporters } \\
$\Phi_{(0,25)}^{X}$ & 0.03 & 0.03 & 0.04 \\
$\Phi_{(50,75)}^{X}$ & 0.24 & 0.20 & 0.22 \\
$\Phi_{(75,100)}^{X}$ & 0.66 & 0.62 & 0.68 \\
\hline \hline
\end{tabular}

Calibration Strategy. The parameters that we use in our calibration are presented in Table 3, while the moments targeted and their model counterparts are presented in Table 4. The moments in the model are computed from a simulated panel of 50, 000 firms followed over 13 time periods (as many periods as we observe in the data), after burning 650 initial periods. ${ }^{34}$

To calibrate the model we follow a Simulated Method of Moments approach. We choose the parameters to minimize the objective function $M W M^{\prime}$, where $M$ is a row vector of the

\footnotetext{
${ }^{32}$ In the sunk cost model we need $\alpha$ only to compute the total external finance. The underlying assumption is that firms face the same working capital requirements in both models.

${ }^{33}$ Total credit balances for manufactures, corresponding to the sectors in our plant-level data.

${ }^{34}$ Note that we avoid simulation approximation errors in comparing the numerical results of the two models by keeping the random number generator seed fixed across simulations.
} 
Table 5: Sales distribution by export status

\begin{tabular}{cccc}
\hline \hline & \multicolumn{3}{c}{ Non-exporters } \\
Total sales & Data & Financial frictions & Sunk costs \\
\hline$\Phi_{(0,25)}^{N X}$ & 0.31 & 0.31 & 0.31 \\
$\Phi_{(25,50)}^{N X}$ & 0.29 & 0.28 & 0.33 \\
$\Phi_{(50,75)}^{N X}$ & 0.25 & 0.26 & 0.24 \\
$\Phi_{(75,100)}^{N X}$ & 0.14 & 0.15 & 0.12 \\
& & Exporters & \\
Total sales & Data & Financial frictions & Sunk costs \\
\hline$\Phi_{(0,25)}^{X}$ & 0.03 & 0.03 & 0.04 \\
$\Phi_{(25,50)}^{X}$ & 0.08 & 0.15 & 0.06 \\
$\Phi_{(50,75)}^{X}$ & 0.24 & 0.20 & 0.22 \\
$\Phi_{(75,100)}^{X}$ & 0.66 & 0.62 & 0.68 \\
\hline \hline
\end{tabular}

log-difference between each target moment and its model counterpart. $W$ is a weighting matrix that allocates the same weight to each of the cross-sectional moments $(i)$ to $(v)$, and also identical weights to each of the distribution moments (vi) to (viii), but proportionally less weight than to the first five moments. ${ }^{35}$ As observed in Table 4 , both models match the target moments almost exactly.

In our calibration strategy we target only three moments of the sales distribution of exporters. While these moments fully characterize the size distribution by export status, below we present the entire distribution for completeness. Table 5 reports the shares of non-exporters and exporters for each quartile of the sales distribution.

Identification. While all parameters affect each of these moments, we provide a heuristic argument for thinking about the mapping between the calibrated parameters and the target moments.

The discount factor $\beta$ affects the external finance to sales ratio. A higher discount factor makes entrepreneurs want to save more, accumulating higher assets, which decreases the

\footnotetext{
35 The weight allocated to the first five moments is ten times more than to the distribution moments, given that we cannot match exactly all the moments.
} 
external finance to sales ratio. ${ }^{36}$ The iceberg trade cost parameter $\tau$ determines the extent to which sales abroad are costlier than domestic sales, thus affecting export intensity. The volatility of the idiosyncratic productivity process $\sigma_{\varepsilon}$ allows us to match the exporter size premium, by affecting the dispersion between high and low productivity firms.

The fixed cost $F$ and domestic working capital usage parameter $\alpha$ allow the model to match the export entry and exit rates. Conditional on being an exporter, and given $\alpha$, different values of $F$ affect the rate at which firms stop exporting. Similarly, conditional on being a non-exporter, and given $F$, different values of $\alpha$ affect the rate at which firms become exporters. ${ }^{37}$

In the sunk cost model parameters $F$ and $S$ allow us to match the export entry and exit rates. On the one hand, conditional on $F, S$ affects the rate at which non-exporters become exporters. On the other hand, conditional on $S, F$ affects the probability of exporters deciding to leave the export market when they receive a low productivity shock. Note that if we set $S=0$ and keep all other parameters fixed, we cannot match both entry and exit rates. We find that sunk export entry costs are significant, consistent with previous literature which estimates them to be large in various sources of microdata. ${ }^{38}$

The autocorrelation of productivity, $\rho$, affects the sales distribution of firms. In general, a higher $\rho$ leads to higher dispersion in the productivity distribution: there is a higher mass of firms with small and large productivity. Given that the former were not exporting in any case, this increases the share of exporters. This is because some of these firms have now a productivity shock high enough that it is now profitable to pay the sunk and fixed costs and export. For the same reason, there is a higher fraction of large firms among exporters.

\footnotetext{
${ }^{36}$ In the financial frictions model $\beta=0.83$, a relatively low value. In our model firms are infinitely lived, but in models in which firms face a death probability every period (for instance, Arellano et al., 2012), the effective rate at which firms discount the future is around 0.86 , a value close to ours.

37 We estimate a value of $\alpha=0.53$. In Section 5.3 of the online appendix we find that the asymmetry in working capital needs implied by the model is consistent with values estimated from the data.

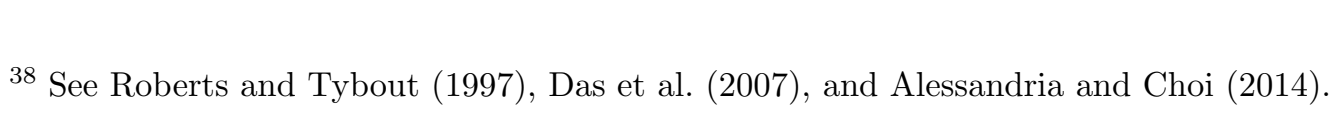


In the sunk cost model, this effect increases the share of very large exporters. In contrast, there is an additional effect in the financial frictions model: a higher $\rho$ increases the share of medium-sized exporters. This is because it increases the incentives to accumulate assets and export for medium-sized constrained firms that received a relatively good productivity shock. The values found for $\rho$ in the benchmark calibration for both models are in the range of values considered in related literature (for references, see Moll, 2014).

Finally, the share of firms with low fixed and sunk costs, $\eta$, and the value of the low fixed and sunk costs, $\kappa(F+S)$, are needed to match the remaining two moments of the sales distribution of exporters, in particular the low tail of the distribution.

\subsection{New exporter dynamics}

In this section, we use the financial frictions model to simulate a panel of firms and compute the new exporter dynamics discussed in Section 2. We compare the simulated moments with those from the data, and with those implied by an analogous simulation of the sunk cost model. The results are presented in Figures 5 to 7 .

Figure 6: Export exit rate

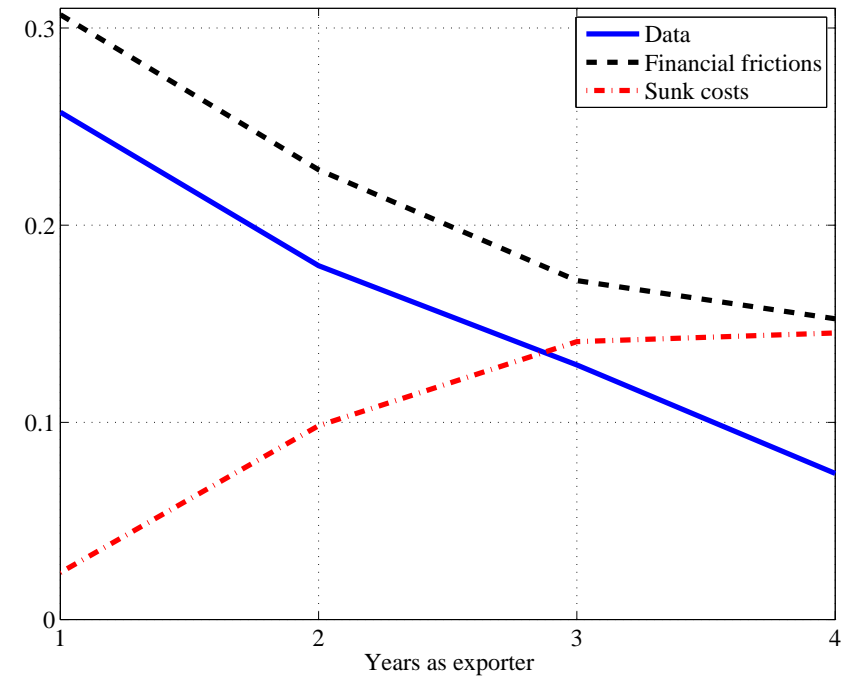

Export exit rate. Figure 6 presents the median export exit rate across cohorts of new exporters, for each of the first four years since becoming an exporter. Consistent with the 
data, we find that our model implies a decreasing export exit rate. In contrast, we find that the sunk cost model differs from the data series, implying an increasing export exit rate. In this model, the export entry threshold is above the exit threshold. Thus, upon entry, firms are far away from the exit threshold. As firms age in the export market, the mass of firms close to the exit threshold initially increases, therefore increasing the exit rate.

Figure 7: Export sales growth

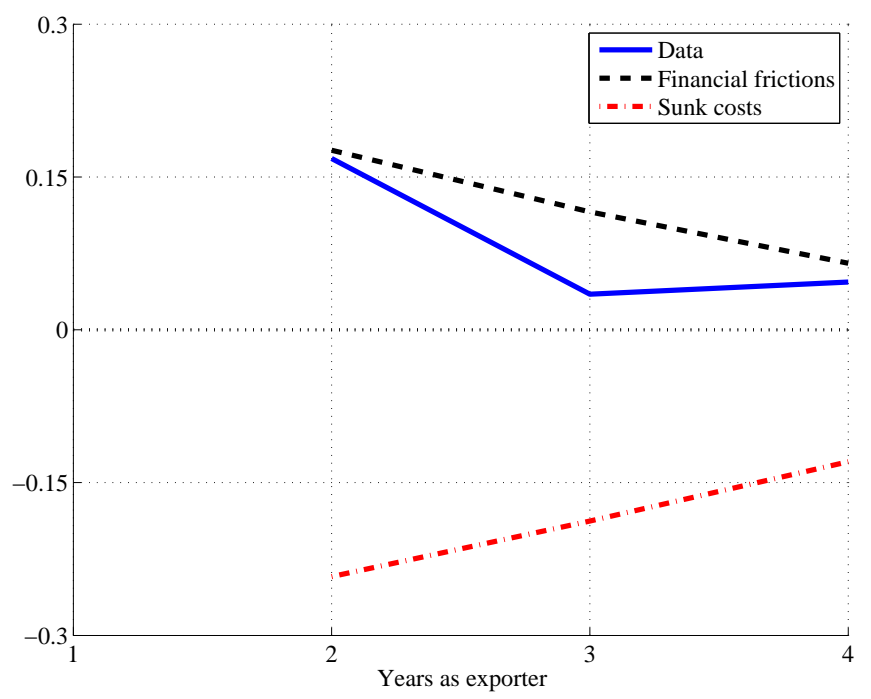

Exports growth. Figure 7 presents the median exports growth rate across the set of firms that export for at least four consecutive periods. We restrict attention to this set of firms to keep the sample size constant and avoid changes in the composition of exporters from affecting the statistics that we study. Both in our model and in the data, firms exhibit positive exports growth over the first few periods after entering the export market.

On the other hand, the sunk cost model implies a negative exports growth rate. In this model, firms become exporters upon receiving a large positive productivity shock. When this happens, they are able to operate at their optimal scale - thus, in contrast to our model, the magnitude of their sales in each market is determined only by their idiosyncratic productivity. Therefore, with autoregressive idiosyncratic productivity, as a cohort of exporters ages, their average productivity decreases implying that their sales in the foreign market decrease as well. 


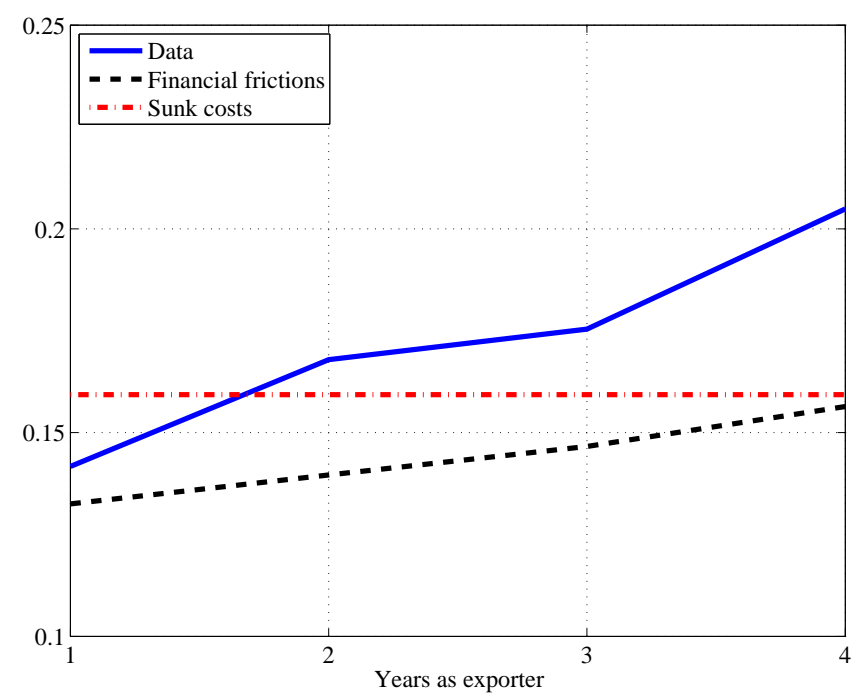

Export intensity. Figure 8 presents the median export intensity across the set of firms that export for at least four consecutive periods. Our model implies that export intensity increases from 0.133 to 0.156 over their first four years in the export market, while in the data it raises from 0.142 to 0.205 . Thus, our model captures 37 percent of export intensity growth. In contrast, the sunk cost model implies a flat export intensity. To the extent that demand functions do not change over time, firms allocate sales across markets in a constant ratio. $^{39}$

In summary, we find that the financial frictions model can largely account for the dynamics of new exporters observed in the data. In contrast, we find that the sunk cost model cannot account for these facts: as firms begin to export, their export exit rate increases, exports decline, and export intensity remains constant. ${ }^{40}$ These findings suggest that it is frictions in financial markets, rather than sunk export entry costs, that drive the dynamics

39 Given our calibration strategy, the financial frictions model captures only a fraction of the export intensity growth observed in the data. However, it is possible for the model to capture 100 percent of the export intensity growth. This can be achieved if the extra working capital required for exporting was larger, at the expense of over-estimating the median export intensity and under-estimating the aggregate external finance. For more details see the online appendix.

${ }^{40}$ In the online appendix, Section 1, we examine the robustness of our results to alternative specifications 
of new exporters.

\subsection{Other features of new exporter dynamics}

In this section we provide evidence in support of our mechanism by studying the performance of our model along other dimensions related to marginal exporters that are not targeted in the calibration strategy. In particular, we study the implications of our model for $(i)$ the dynamics of domestic sales growth upon entry to the export market, (ii) the dynamics of external finance upon entry to the export market, and (iii) the rate at which firms that recently stopped exporting choose to re-enter the foreign market.

Figure 9: Domestic sales growth

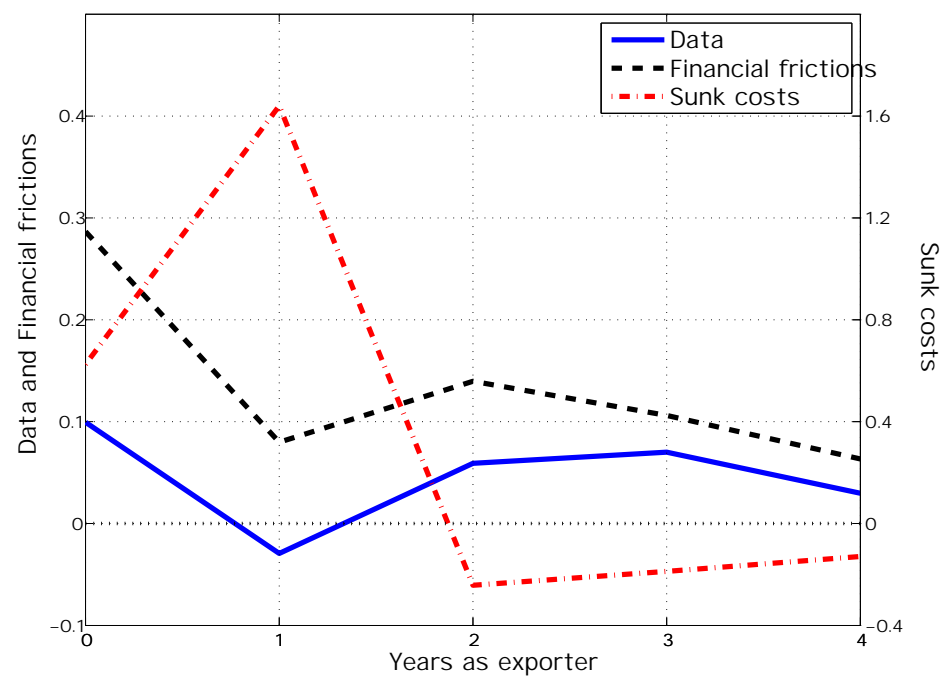

Domestic sales growth. Figure 9 presents the median domestic sales growth rate across the set of firms that export for at least four consecutive periods, and which sell domestically for at least one period before becoming exporters. ${ }^{41}$ In the data, firms feature negative domestic sales growth upon entry to the foreign market, while domestic sales growth is

of our benchmark sunk cost model.

${ }^{41}$ We exclude firms that export upon birth to keep the sample size constant over time, avoiding the growth of domestic sales from being driven by changes in the composition of the cohort. 
positive thereafter. We examine the robustness of this finding in Appendix A.2. ${ }^{42}$

Our model captures the decline in the growth of domestic sales upon entry to the export market, and also implies dynamics similar to the data thereafter. ${ }^{43}$ This follows from the fact that firms that start exporting are, to a large extent, financially constrained. As they enter the foreign market, they reallocate assets from the domestic market into the financing of foreign sales, which leads to a decline in the growth rate of domestic sales.

Instead, the sunk cost model implies an increase in the domestic sales growth rate upon entry to the foreign market, while implying negative growth thereafter. Furthermore, notice that the magnitude of the increase upon entry is much larger than in our model. As discussed earlier in this setup, new exporters are firms hit with very large productivity shocks which push them above the export entry threshold. Given that firms operate at their optimal scale, the large productivity shocks translate into very large sales growth across all markets - in particular, in the domestic market. Following entry, with autoregressive productivity shocks, firms' productivity decreases on average resulting in negative domestic sales growth.

External finance dynamics. A fundamental ingredient of our mechanism is that firms are largely financially constrained when they begin to export. Over time, they accumulate assets, allowing them to increase the amount of external finance borrowed and their scale of operation. In this subsection, we examine the dynamics of external finance implied by our model and contrast them with their empirical counterpart.

While the Chilean plant-level data does not provide us with a direct measure of total external finance used, we do observe several measures of plant-level financial costs. We restrict attention to two of these measures: $(i)$ total financial expenditures, and ( $i i$ ) total

\footnotetext{
42 In contemporaneous work, Blum et al. (2013) document a related finding among Chilean plants.

43 For a small enough share of firms with low export entry costs, our model can account for a negative rate of domestic sales growth upon entry to the foreign market. See Section 3 in the online appendix for the quantitative results implied by a specification of our model with homogeneous export entry costs.
} 
bank-related financial expenditures. ${ }^{44}$

Let $E F$ denote the total amount of external finance used by a plant in the model to finance its operations. In our model, this amount is given by $E F=\max \left\{\alpha w n+e^{\prime}\left[w F+w n^{*}\right]-a, 0\right\}$. That is, if asset-holdings are sufficient to pay for labor costs, then the plant does not use external finance; otherwise, the plant borrows to pay for these costs. We compute this measure for both the financial frictions and sunk cost models. ${ }^{45}$

While we do not directly observe an empirical counterpart to $E F$, we do observe a measure of the plants' level of financial expenditures. Therefore, we compute the level of financial expenditures $G$ implied by the model and compare it with its empirical counterpart $\widehat{G}$. Given an intra-period interest rate $r_{\text {intra }}$, the financial expenditures faced by a plant in the model borrowing an amount $E F$ are given by $G=r_{\text {intra }} E F{ }^{46}$ We compare the growth rate of financial expenditures in the data, $\Delta \ln \widehat{G}$, with the one in the model, $\Delta \ln G$. Given that we assume $r_{\text {intra }}$ is constant, the dynamics of financial expenditures are identical to those of the stock of external finance: that is, we have that $\Delta \ln G=\Delta \ln E F$.

Figure 10 plots the average $\Delta \ln G$ and $\Delta \ln \widehat{G}$ among cohorts of new exporters. Given our interest in the dynamics of external finance, we restrict attention to firms with positive levels of external finance. We observe that the dynamics of external finance implied by our model

${ }^{44}$ Our measure of total financial expenditures consists of the sum of $(a)$ allowances and participations of the board of directors, $(b)$ donations, fines, and others, $(c)$ bank commissions, $(d)$ interests, $(e)$ dividends related to bank debt, $(f)$ losses due to sales of fixed assets, $(g)$ exchange rate adjustments, $(h)$ other adjustments, and $(i)$ other expenditures. Our measure of total bank-related financial expenditures is the sum of $(c),(d)$, and $(e)$.

45 While firms in both models are subject to working capital needs and financing, only firms in the financial frictions model are subject to constraints that prevent them from successfully satisfying these requirements. In other words, we assume that firms in both models are subject to the working capital constraint, only that this constraint never binds in the sunk cost model given that $\lambda=\infty$.

46 Note that in our baseline specification we assume that $r_{\text {intra }}=0$, which implies that financial expenditures are equal to zero. The above results hold for any arbitrarily small interest rate. Using $r_{\text {intra }}>0$, but small, does not affect our results. 
Figure 10: External finance dynamics

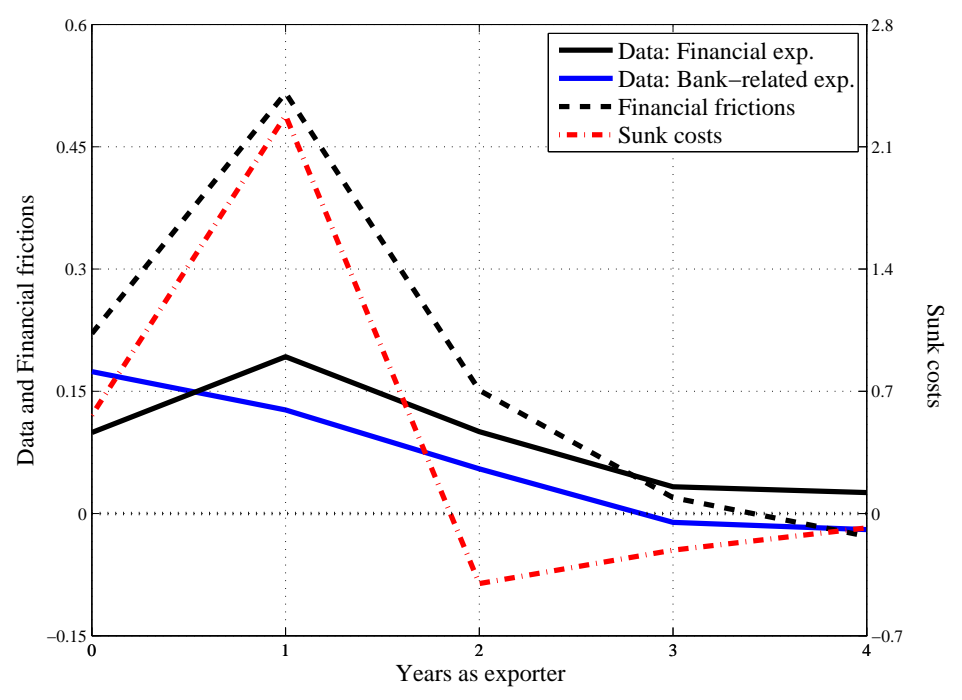

are consistent with those observed in the data: the growth of external finance is highest upon entry, and decreases thereafter, getting close to zero by the fourth year in the export market. On the other hand, the sunk cost model implies very large growth upon entry, followed by negative growth after the first period. In this model, the growth of external finance upon entry is more than five times as large as in the financial frictions model.

Stoppers. While financial frictions appear to play a key role in accounting for firms' export entry decisions and their dynamics, it is also important to examine the forces that drive firms' decisions to stop exporting. After all, financial frictions may distort international trade flows along the extensive margin either by increasing exit or by reducing entry. Therefore, we now study the implications of our model for firms that stop exporting.

We begin by examining the extent to which our model can account for the dynamics of export re-entry observed in the data. Figure 11 plots the share of plants that choose to re-enter the foreign market within any of the first four years after they stopped exporting in the data, and compare them with the same statistics in our model with financial frictions and the sunk cost model. In the data, we observe that 29 percent of firms that stopped exporting choose to re-enter the export market in the following year. This share is decreasing in the number of years after the exit from the export market. We find that our model can capture 
these features of the data. In contrast, the sunk cost model is largely at odds with the data: only a very small share of new non-exporters (1 percent of them) re-start exporting in the following year, and this fraction is increasing in the number of periods since the last foreign transaction.

Figure 11: Non-exporters re-entry rate

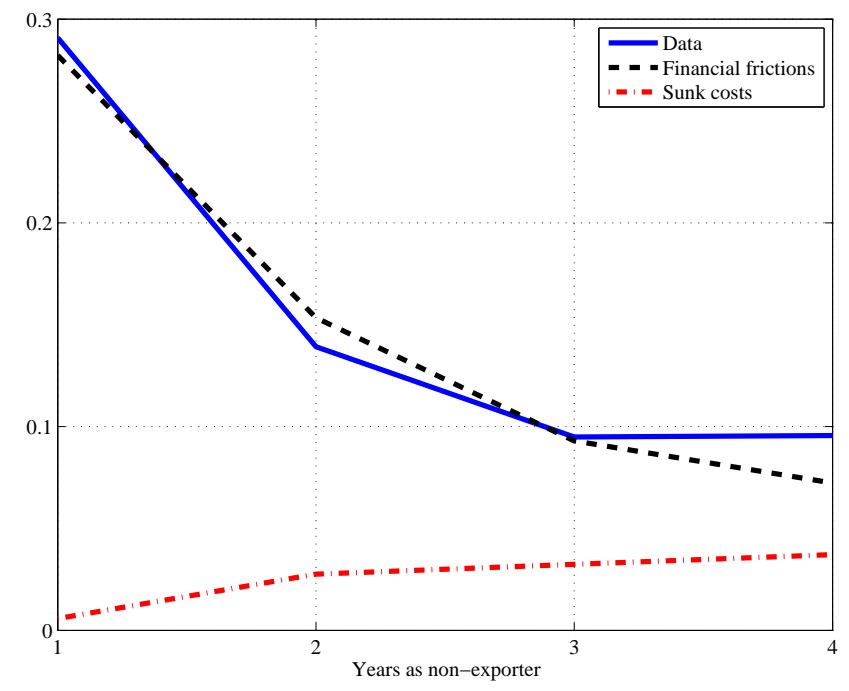

We now examine the relative size, as measured by the median number of workers, of new non-exporters relative to both exporters and non-exporters. ${ }^{47}$ The results are reported in Table 6. In the data, we observe that new non-exporters are approximately half as large as the median exporter, approximately two-and-a-half times as large as the median nonexporter, and 12 percent smaller than the median new exporter. The financial frictions model is largely in line with these patterns of the data. In contrast, the sunk cost model implies that new non-exporters are approximately the same size as non-exporters at odds with the data, and much smaller than exporters.

In summary, we find that our financial frictions model is largely consistent with key features of the export re-entry dynamics and relative sizes of new non-exporters, while the sunk cost model misses this statistics. We interpret these findings as evidence in support of our mechanism as a key driver of firms' export entry and exit decisions.

\footnotetext{
47 "New non-exporters" are non-exporters that exported in the previous year. "New exporters" are exporters that didn't export the period before.
} 
Table 6: Median number of workers

\begin{tabular}{cccc}
\hline \hline & Data & Financial frictions & Sunk costs \\
\hline New non-exporters / Exporters & 0.52 & 0.59 & 0.19 \\
New non-exporters / Non-exporters & 2.50 & 2.83 & 0.93 \\
New non-exporters / New exporters & 0.88 & 0.53 & 0.09 \\
\hline \hline
\end{tabular}

\section{Policy analysis}

In the previous sections we documented that, in contrast to standard models of international trade with sunk export entry costs, the model with financial frictions can largely account for the observed behavior of both new exporters and stoppers. This suggests that it is frictions in financial markets, and not sunk export entry costs, that are more likely to determine firms' export entry decisions. In this section, we investigate the policy implications of this finding. In particular, we study two policy experiments. First, we investigate how financial constraints affect the impact of a trade liberalization, relative to the implications of the frictionless sunk cost model. In our second experiment, we use our model to study the effect of policies aimed at reducing the impact of financial frictions. Given the partial equilibrium nature of our model, we interpret our results as applying to a particular industry rather than the whole economy. ${ }^{48}$

\subsection{Trade Liberalization}

Following a large literature in international trade, in this section we investigate how financial frictions affect the impact of a trade liberalization by studying the effect of a reduction in the variable trade costs faced by firms.

We begin by analyzing the impact of a reduction of $\tau$ by 0.10 on the steady-state allocations implied by our financial frictions model. We interpret our first experiment as a 10 percentage point reduction in tariffs. ${ }^{49}$ We are interested in the impact of this change in $\tau$

${ }^{48}$ For a general equilibrium analysis of financial development in a closely related model, see Leibovici (2014). 49 Anderson and van Wincoop (2004) report that policy related costs of trade in Chile were about 10 percent in 1999 and, hence, one can interpret this policy as a move to an environment without tariffs. Note that, 
on the following industry-level variables: exports and total sales, export intensity, the share of exporters, and median exports. We then contrast these results with those implied by the sunk cost model when subject to the same change in $\tau$. We interpret any differences across the models in their response to a change in $\tau$ as informative of the role of financial frictions in distorting the industry-level response to a trade liberalization.

Table 7: Effects of a trade liberalization

\begin{tabular}{cccc}
\hline \hline \multicolumn{4}{c}{ Percentage changes with respect to benchmark } \\
& Financial Frictions & Sunk Costs & Difference \\
Exports & $53.4 \%$ & $64.6 \%$ & $-11.2 \mathrm{pp}$ \\
Total Sales & $3.1 \%$ & $6.2 \%$ & $-3.1 \mathrm{pp}$ \\
Exports / Total Sales & $48.8 \%$ & $55.0 \%$ & $-6.2 \mathrm{pp}$ \\
\hline Share of Exporters & $26.4 \%$ & $51.1 \%$ & $-24.7 \mathrm{pp}$ \\
Median Exports & $20.7 \%$ & $18.3 \%$ & $2.4 \mathrm{pp}$ \\
\hline \hline
\end{tabular}

Notes: We report percentage changes implied by a change in $\tau$ from its benchmark value $\tau=1.513$ in the financial frictions model, and $\tau=1.516$ in the sunk cost model.

Table 7 reports the results of our policy experiment. Following the trade liberalization, in the sunk cost model, foreign sales are 64.6 percent higher than in the benchmark calibration, while total sales are 6.3 percent higher. In contrast, in the financial frictions model, foreign sales increase by 53.4 percent (11.2 percentage points smaller increase than observed in the sunk cost model) while total sales increase by only 3.1 percent (half of the growth rate implied by the sunk cost model). Thus, the trade liberalization has a substantially smaller effect on foreign and domestic sales in the financial frictions model compared to the sunk cost model.

In addition, while median exports increase by a similar amount in both models, the share of exporters in the sunk cost model increases twice as much as in the financial frictions model. This suggests that financial frictions decrease the gains from trade liberalization mainly by distorting the extensive margin of trade.

in such case, we would have that $\tau>1$ even after tariffs are eliminated, which is consistent with the existence of non-tariff trade barriers and other variable trade costs. 
To better understand why trade liberalization results in a smaller increase in foreign and total sales in the financial frictions model, note that a reduction in tariffs decreases the marginal cost of exporting. This translates into both higher profits, for any given level of exports, as well as a higher optimal scale of exporting. In the sunk cost model both of these effects encourage entry, while the latter effect also implies an increase in the foreign sales per exporter. In the financial frictions model, however, a large fraction of firms are financially constrained. Having low levels of assets, these firms are unable to achieve a scale large enough to take advantage of the lower tariffs. Therefore, these firms choose not to export and the share of exporters increases less than in the sunk cost model (see Table 7). The lower increase in the share of exporters translates then into a lower increase in foreign sales, and thus in total sales, in the financial frictions model compared to the sunk cost model.

Besides this effect, in the financial frictions model total sales are additionally lower because domestic sales decrease when trade costs are lower. Given that exporters have limited assets, they substitute domestic for foreign sales in order to take advantage of the reduction in the marginal cost of exports. As a result the increase in foreign sales is more similar across models than the change in total sales. ${ }^{50}$

The results above suggest that financial frictions limit the positive effects of a trade liberalization. In order to quantify the cost of the financing constraint, we ask: by how much would variable trade costs need to decline in the financial frictions model in order to deliver the same changes in total sales as implied by the sunk cost model? We refer to this

\footnotetext{
${ }^{50}$ More precisely, let $N$ be number of firms and $x^{\prime}$ denote the export sales per exporter in the new steady state. A change in total sales $(\Delta Y)$ can be decomposed as:

$$
\Delta Y=\Delta(D S)+N \Delta(S X) x^{\prime}+N \Delta(x) S X
$$

where $\Delta(D S)$ is the change in total domestic sales, $\Delta(S X)$ is the change in the share of exporters, and $\Delta(x)$ is the change in exports per exporter. In the sunk cost model the contribution of each factor to total sales growth is 0 percent, 80 percent, and 20 percent, respectively, while in the financial frictions model these are -21 percent, 62 percent, and 55 percent.
} 
difference as the tariff equivalent cost of financial frictions. Table 8 reports the values of these costs corresponding to a reduction in $\tau$ of 5 and 10 percentage points.

Table 8: Tariff equivalent costs of financial frictions

\begin{tabular}{ccc}
$\Delta \tau$ with sunk costs & Implied $\Delta \tau$ with financial frictions & Tariff equivalent \\
-0.05 & -0.096 & $0.046(91.2 \%)$ \\
-0.1 & -0.167 & $0.054(67.5 \%)$ \\
\hline \hline
\end{tabular}

According to Table 8, in order for the model with financial frictions to deliver the same increase in total sales in response to a trade liberalization as the sunk cost model, tariffs would have to decrease by an additional 4.6 percentage points when considering a 5pp reduction in tariffs, and by an additional $6.7 \mathrm{pp}$ when we consider a 10pp decrease in tariffs. These cost reductions are more than 60 percent larger than the reductions in variable trade costs considered in the sunk cost model. Thus, the results in Table 7 and Table 8 suggest that financial frictions substantially reduce the effects of a trade liberalization.

\subsection{Financial Development}

In this section, we study the industry-level effects of policies aimed at reducing the impact of financial frictions. We do so by investigating the impact of an increase in the amount that can be borrowed per unit of collateral, $\lambda$, keeping all other parameters constant. We then contrast the allocations implied by our baseline calibration with those implied by our counterfactual experiments. We first relax financial frictions by setting $\lambda=1.77$, which corresponds to the value of collateral per dollar borrowed observed in the Eurozone in early and mid 2000s. ${ }^{51}$ We then examine the allocations implied by a model without financial frictions $(\lambda=\infty)$, as well as the case of financial autarky $(\lambda=1)$.

We first analyze the implications of alternative values of $\lambda$ on exports and total sales. Table 9 shows that relaxing the collateral requirements from 1.56 (benchmark) to 1.3 (Euro-

\footnotetext{
51 The above number corresponds to the average of the collateral requirements across Germany, Greece, Ireland, Portugal, and Spain, as reported in the WBES dataset.
} 
Table 9: Effects of changes in the collateral constraint

\begin{tabular}{|c|c|c|c|}
\hline \multicolumn{4}{|c|}{ Percentage changes with respect to benchmark, $\lambda=1.64$} \\
\hline & $\begin{array}{c}\text { Eurozone } \\
\lambda=1.77\end{array}$ & $\begin{array}{c}\text { No Frictions } \\
\quad \lambda=\infty\end{array}$ & $\begin{array}{c}\text { Autarky } \\
\lambda=1\end{array}$ \\
\hline Collateral per $\$$ borrowed & 1.29 & 0 & $\infty$ \\
\hline Exports & $7.4 \%$ & $83.7 \%$ & $-44.0 \%$ \\
\hline Total Sales & $2.5 \%$ & $29.3 \%$ & $-19.0 \%$ \\
\hline Exports / Total Sales & $4.7 \%$ & $42.1 \%$ & $-30.9 \%$ \\
\hline Share of exporters & $3.5 \%$ & $39.6 \%$ & $-24.2 \%$ \\
\hline Median Exports & $6.7 \%$ & $25.9 \%$ & $-43.9 \%$ \\
\hline
\end{tabular}

zone) units of collateral per dollar borrowed, ${ }^{52}$ leads to a 7.4 percent increase in exports, 2.5 percent increase in total sales, and 4.7 percent growth in the exports to sales ratio. Thus, our results suggest only moderate gains in Chile, for any particular industry, from liberalizing financial markets to the level observed in Eurozone.

Note that the results in Table 9 do not necessarily imply that financial frictions are unimportant. On the contrary, shutting down financial markets results in a 19 percent fall in sales and a 44 percent drop in exports. They rather point to the fact that the difference in the financial markets' efficiency between Chile and the Eurozone does not translate into large differences in a particular industry's total sales or exports.

Next we analyze the implications of alternative values of $\lambda$ on the intensive and extensive margins of trade. Relaxing the financial constraint to the level observed in the Eurozone increases the share of exporters by 3.5 percent and the median exports by 6.7 percent. As in the case of exports and total sales, both moving to autarky and eliminating financial frictions lead to much larger changes also in the share of exporters and median exports. Moving to autarky is associated with a 24.2 percent fall in the share of exporters and a 43.9 percent fall in median exports. This suggests that the intensive margin of trade becomes relatively more

\footnotetext{
52 These numbers correspond to $\lambda=1.64$ and $\lambda=1.77$, respectively, since collateral per dollar borrowed in the model is given by $\frac{a}{(\lambda-1) a}$.
} 
distorted compared to the extensive margin when financial constraints are very severe. On the other hand, an economy with no financial frictions implies a 39.6 percent increase in the share of exporters with respect to the benchmark economy, while median exports increase by 25.9 percent. This suggests that when financial constraints are relatively lax, it is the extensive margin that becomes a driving force for growth in foreign and domestic sales. ${ }^{53}$

The empirical trade literature provides mixed results on the relative importance of the intensive and extensive margin distortions due to financial frictions. Manova (2013) finds that the intensive margin is more important than the extensive margin. On the other hand, Berman and Hericourt (2010) find that financial frictions heavily distort export entry decisions but find no evidence of their impact on the volume of exports, while Minetti and Zhu (2011) find that both margins are heavily distorted by financing constraints. Our results may help to reconcile the findings by the previous literature, since our model predicts that whether financial frictions distort more the intensive or the extensive margins of trade for a given industry depends on the severity of the financial frictions and the share of firms facing small export entry costs.

\section{Conclusion}

In this paper, we investigate the extent to which frictions in financial markets distort firms' export decisions, acting as a barrier to international trade, by studying their implications for new exporter dynamics. We introduce financial constraints to a standard model of international trade: firms need to pay in advance their labor costs and a fixed cost if they export, subject to a borrowing constraint that depends on the amount of assets they hold

\footnotetext{
${ }^{53}$ We should note, however, that these results are partially driven by the share of firms that face small export entry costs in our model. Since these firms would export even in the case of autarky, albeit very small quantities, their exports can only be driven by financial constraints through the intensive margin. In a financially developed economy, where the share of these firms among total exporters is smaller, the extensive margin plays a larger role. This is also the case if instead every firm faced the same fixed cost: then the extensive margin would be the predominant channel through which financial development affects total exports. Section 3 of the online appendix reports these results.
} 
as collateral. This friction allows us to capture both new exporter dynamics and the cross sectional facts matched by standard models. Thus, our framework is a simple alternative to standard trade models with sunk costs, which cannot account for new exporter dynamics, and hence miss important aspects of export entry and exit decisions. Furthermore, we provide evidence, using firm-level data from Chile, that supports our mechanism and distinguishes it from alternative explanations. We find that the effects of a trade liberalization crucially depend on whether export entry and exit decisions are assumed to be driven by financing constraints or sunk costs. In particular, the effects of lowering trade barriers on total sales and exports are substantially lower in the model with financial frictions compared to the sunk cost model. Financial frictions distort export decisions mostly through the extensive margin, thereby suggesting that there are significant gains from financial development.

\section{APPENDIX}

\section{A.1. Proofs}

Proposition 1. The solution to the firm's static problem in the frictionless economy is given by optimal labor demand schedules for domestic and foreign production, $\hat{n}$ and $\hat{n}^{*}$ respectively, and a constant threshold level of productivity $z=\bar{z}$, such that a firm exports if its productivity is above $\bar{z}$, and produces only domestically otherwise, where

1. $\hat{n}$ and $\hat{n}^{*}$ are given by

$$
\hat{n}=\left[\left(\frac{\sigma}{\sigma-1}\right) \frac{w}{P Q^{1 / \sigma}}\right]^{-\sigma} z^{\sigma-1}, \quad \hat{n}^{*}=\left[\left(\frac{\sigma}{\sigma-1}\right) \frac{w}{P^{*}\left(Q^{*}\right)^{1 / \sigma}}\right]^{-\sigma} \tau^{1-\sigma} z^{\sigma-1}
$$

2. $z=\bar{z}$ is given by

$$
\bar{z}=\frac{1}{\sigma-1}(w F)^{\frac{1}{\sigma-1}}\left[\sigma \frac{1}{P^{*}\left(Q^{*}\right)^{1 / \sigma}}\right]^{\frac{\sigma}{\sigma-1}} w \tau
$$

3. Optimal sales in the domestic and foreign markets are, respectively, $\hat{p} \hat{q}=(z \hat{n})^{\frac{\sigma-1}{\sigma}} Q^{\frac{1}{\sigma}} P$ and $\hat{p}^{*} \hat{q}^{*}=\left(\frac{z}{\tau} \hat{n}^{*}\right)^{\frac{\sigma-1}{\sigma}} Q^{* \frac{1}{\sigma}} P^{*}$. Export intensity is constant, and it is given by:

$$
\frac{\hat{p}^{*} \hat{q}^{*}}{\hat{p} \hat{q}+\hat{p}^{*} \hat{q}^{*}}=\frac{\frac{P^{* \sigma} Q^{*}}{\tau^{\sigma-1}}}{P^{\sigma} Q+\frac{P^{* \sigma} Q^{*}}{\tau^{\sigma-1}}}
$$


if the firm exports, 0 otherwise.

Proof. Recall that the static problem of a firm with productivity $z$ (in the absence of sunk costs and without financial frictions) is given by:

\section{Firm's Problem}

$$
\begin{aligned}
& \pi(z)=\max _{n, n^{*}, q, q^{*}, e^{\prime} \in\{0,1\}} p q-w n+e^{\prime}\left[p^{*} q^{*}-w n^{*}-w F\right] \\
& \text { s.t. } \\
& n=\frac{q}{z}, \quad n^{*}=\frac{\tau q^{*}}{z} \\
& q=\left(\frac{p}{P}\right)^{-\sigma} Q, \quad q^{*}=\left(\frac{p^{*}}{P^{*}}\right)^{-\sigma} Q^{*}
\end{aligned}
$$

This can be rewritten as a maximization problem in $q, q^{*}$ and $e^{\prime}$ :

$$
\pi(z)=\max _{q, q^{*}, e^{\prime} \in\{0,1\}} P Q^{\frac{1}{\sigma}} q^{1-\frac{1}{\sigma}}-w \frac{q}{z}+e^{\prime}\left[P^{*} Q^{* \frac{1}{\sigma}} q^{* 1-\frac{1}{\sigma}}-w \frac{\tau q}{z}-w F\right]
$$

The First Order Conditions for the above problem are given by:

$$
\left(1-\frac{1}{\sigma}\right) P Q^{\frac{1}{\sigma}} q^{\frac{1}{\sigma}}=\frac{w}{z}
$$

and (in the case $\mathrm{e}^{\prime}=1$ ),

$$
\left(1-\frac{1}{\sigma}\right) P^{*} Q^{* \frac{1}{\sigma}} q^{* \frac{1}{\sigma}}=\frac{\tau w}{z}
$$

Note that these two F.O.C. are independent of each other and hence we can solve them separately. Let $\hat{q}$ be the optimal level of production for the domestic market and $\hat{q}^{*}$ be the optimal level of production for the foreign market. Then

$$
\begin{aligned}
& \hat{q}=\left[\left(\frac{\sigma}{\sigma-1}\right) \frac{w}{P Q^{\frac{1}{\sigma}}}\right]^{-\sigma} z^{\sigma} \\
& \hat{q}^{*}=\left[\left(\frac{\sigma}{\sigma-1}\right) \frac{w}{P^{*} Q^{* \frac{1}{\sigma}}}\right]^{-\sigma}\left(\frac{z}{\tau}\right)^{\sigma}
\end{aligned}
$$


It follows that optimal domestic and foreign labor demands are given by:

$$
\begin{aligned}
& \hat{n}=\left[\left(\frac{\sigma}{\sigma-1}\right) \frac{w}{P Q^{\frac{1}{\sigma}}}\right]^{-\sigma} z^{\sigma-1} \\
& \hat{n}^{*}=\left[\left(\frac{\sigma}{\sigma-1}\right) \frac{w}{P^{*} Q^{* \frac{1}{\sigma}}}\right]^{-\sigma}\left(\frac{z}{\tau}\right)^{\sigma-1}
\end{aligned}
$$

Note that because of the constant returns to scale technology, in the firctionless economy, firm's profits from the domestic market are independent of it export decision. Therefore, the firm will export if and only if

$$
\hat{p^{*}} \hat{q}^{*}-w \hat{n}^{*}-w F \geq 0
$$

The above condition is equivalent to

$$
\frac{1}{\sigma}\left(\frac{\sigma}{\sigma-1}\right)^{-(\sigma-1)}\left(\frac{z}{w \tau}\right)^{\sigma-1} P^{* \sigma} Q-w F \geq 0
$$

The threshold level of productivity $z=\bar{z}$, such that a firm exports if its productivity is above $\bar{z}$, and produces only domestically otherwise, is the solution to:

$$
\frac{1}{\sigma}\left(\frac{\sigma}{\sigma-1}\right)^{-(\sigma-1)}\left(\frac{\bar{z}}{w \tau}\right)^{\sigma-1} P^{* \sigma} Q-w F=0
$$

Rearranging the above expression yields

$$
\bar{z}=\frac{1}{\sigma-1}(w F)^{\frac{1}{\sigma-1}}\left[\sigma \frac{1}{P^{*}\left(Q^{*}\right)^{1 / \sigma}}\right]^{\frac{\sigma}{\sigma-1}} w \tau
$$

We now compute the export intensity implied by the firms optimal choices. The export intensity is defined as:

$$
\frac{\hat{p}^{*} \hat{q}^{*}}{\hat{p}^{*} \hat{q}^{*}+\hat{p} \hat{q}}
$$

We use the fact that $\hat{p} \hat{q}=(z \hat{n})^{\frac{\sigma-1}{\sigma}} Q^{\frac{1}{\sigma}} P$ and $\hat{p}^{*} \hat{q}^{*}=\left(\frac{z}{\tau} \hat{n}^{*}\right)^{\frac{\sigma-1}{\sigma}} Q^{* \frac{1}{\sigma}} P^{*}$. Then:

$$
\frac{\hat{p}^{*} \hat{q}^{*}}{\hat{p}^{*} \hat{q}^{*}+\hat{p} \hat{q}}=\frac{\left(\frac{z}{\tau} \hat{n}^{*}\right)^{\frac{\sigma-1}{\sigma}} Q^{* \frac{1}{\sigma}} P^{*}}{\left(\frac{z}{\tau} \hat{n}^{*}\right)^{\frac{\sigma-1}{\sigma}} Q^{* \frac{1}{\sigma}} P^{*}+(z \hat{n})^{\frac{\sigma-1}{\sigma}} Q^{\frac{1}{\sigma}} P}
$$


Using the expressions for $\hat{n}$ and $\hat{n^{*}}$ derived above we can rewrite export intensity as:

$$
\frac{\left(\frac{P^{*} Q^{* \frac{1}{\sigma}}}{\tau}\right)^{\sigma-1} P^{*} Q^{* \frac{1}{\sigma}}}{\left(\frac{P^{*} Q^{*} \frac{1}{\sigma}}{\tau}\right)^{\sigma-1} P^{*} Q^{* \frac{1}{\sigma}}+\left(P Q^{\frac{1}{\sigma}}\right)^{\sigma-1} P Q^{\frac{1}{\sigma}}}=\frac{\frac{P^{* \sigma} Q^{*}}{\tau^{\sigma-1}}}{\frac{P^{* \sigma} Q^{*}}{\tau^{\sigma-1}}+P^{\sigma} Q}
$$

Proposition 2. Consider a constrained exporter $(\mu>0)$. Then:

1. Export sales are given by

$$
p^{*} q^{*}=P^{* \sigma} Q^{*}\left[\frac{w \tau(1+\mu)}{z} \frac{\sigma}{\sigma-1}\right]^{1-\sigma}
$$

2. Export intensity is given by

$$
\frac{p^{*} q^{*}}{p q+p^{*} q^{*}}=\frac{P^{* \sigma} Q^{*}\left[\frac{w \tau(1+\mu)}{z} \frac{\sigma}{\sigma-1}\right]^{1-\sigma}}{P^{\sigma} Q\left[\frac{w(1+\alpha \mu)}{z} \frac{\sigma}{\sigma-1}\right]^{1-\sigma}+P^{* \sigma} Q^{*}\left[\frac{w \tau(1+\mu)}{z} \frac{\sigma}{\sigma-1}\right]^{1-\sigma}}
$$

3. Export sales $p^{*} q^{*}$ and export intensity $\frac{p^{*} q^{*}}{p q+p^{*} q^{*}}$ increase as firms accumulate assets and become less constrained, that is, as $\mu$ decreases.

Proof. The static problem of a firm with productivity $z$ and assets $a$ in the absence of sunk cost and in the presence of financial frictions is given by:

\section{Firm's Problem}

$$
\begin{aligned}
\pi(a, z)= & \max _{n, n^{*}, q, q^{*}, e^{\prime} \in\{0,1\}} p q-w n+e^{\prime}\left[p^{*} q^{*}-w n^{*}-w F\right] \\
& \text { s.t. } \\
& n=\frac{q}{z}, \quad n^{*}=\frac{\tau q^{*}}{z} \\
& q=\left(\frac{p}{P}\right)^{-\sigma} Q, \quad q^{*}=\left(\frac{p^{*}}{P^{*}}\right)^{-\sigma} Q^{*} \\
& \alpha w n+e^{\prime}\left[w F+w n^{*}\right] \leq \lambda a
\end{aligned}
$$


As in the proof of the Proposition 1, we rewrite the above problem as a maximization problem in $q$ and $q^{*}$ :

$$
\begin{gathered}
\pi(a, z)=\max _{q, q^{*}, e^{\prime} \in\{0,1\}} P Q^{\frac{1}{\sigma}} q^{1-\frac{1}{\sigma}}-w \frac{q}{z}+e^{\prime}\left[P^{*} Q^{* \frac{1}{\sigma}} q^{* 1-\frac{1}{\sigma}}-w \frac{\tau q}{z}-w F\right] \\
\alpha w n+e^{\prime}\left[w F+w n^{*}\right] \leq \lambda a
\end{gathered}
$$

The Lagrangian associated with the above problem, when $e^{\prime}=1$, is given by

$$
L=\max _{q, q^{*}} P Q^{\frac{1}{\sigma}} q^{1-\frac{1}{\sigma}}-w \frac{q}{z}+P^{*} Q^{* \frac{1}{\sigma}} q^{* 1-\frac{1}{\sigma}}-w \frac{\tau q^{*}}{z}-w F+\mu\left[\lambda a-\alpha w \frac{q}{z}+w F+w \frac{\tau q *}{z}\right]
$$

Taking first order conditions we get

$$
\begin{aligned}
& \left(1-\frac{1}{\sigma}\right) q^{-\frac{1}{\sigma}} P Q^{\frac{1}{\sigma}}-\frac{w}{z}-\mu \alpha \frac{w}{z}=0 \\
& \left(1-\frac{1}{\sigma}\right) q^{*-\frac{1}{\sigma}} P^{*} Q^{* \frac{1}{\sigma}}-\frac{\tau w}{z}-\mu \frac{\tau w}{z}=0
\end{aligned}
$$

and the complementary slackness condition is given by

$$
\mu\left[\lambda a-\alpha w \frac{q}{z}+w F+w \frac{\tau q *}{z}\right]=0
$$

We use the first order condition for $q^{*}$ to express the optimal quantity of export $\hat{q}^{*}$ as a function of the Lagrange multiplier $\mu$ :

$$
\hat{q}^{*-\frac{1}{\sigma}}=P^{*-1} Q^{*-\frac{1}{\sigma}}\left(\frac{\sigma}{\sigma-1}\right)\left(\frac{\tau w(1+\mu)}{z}\right)
$$

or

$$
\hat{q}^{*}=P^{* \sigma} Q^{*}\left[\frac{\sigma}{\sigma-1} \frac{\tau w(1+\mu)}{z}\right]^{-\sigma}
$$

Recall that $p^{*} q^{*}=P^{*} Q^{* \frac{1}{\sigma}} q^{* 1-\frac{1}{\sigma}}$ and so

$$
\hat{p}^{*} \hat{q}^{*}=P^{*} Q^{* \frac{1}{\sigma}}\left(P^{* \sigma} Q^{*}\left[\frac{\sigma}{\sigma-1} \frac{\tau w(1+\mu)}{z}\right]^{-\sigma}\right)^{1-\frac{1}{\sigma}}=P^{* \sigma} Q^{*}\left[\frac{\sigma}{\sigma-1} \frac{\tau w(1+\mu)}{z}\right]^{1-\sigma}
$$


Similarly, one can show that the optimal quantity and optimal sales in the domestic markets are given by

$$
\begin{aligned}
& \hat{q}=P^{\sigma} Q\left[\frac{\sigma}{\sigma-1} \frac{w(1+\alpha \mu)}{z}\right]^{-\sigma} \\
& \hat{p} \hat{q}=P^{\sigma} Q\left[\frac{\sigma}{\sigma-1} \frac{w(1+\alpha \mu)}{z}\right]^{1-\sigma}
\end{aligned}
$$

Using the expression for the optimal domestic and foreign sales derived above we get:

$$
\frac{\hat{p}^{*} \hat{q}^{*}}{\hat{p}^{*} \hat{q}^{*}+\hat{p} \hat{q}}=\frac{P^{* \sigma} Q^{*}\left[\frac{\sigma}{\sigma-1} \frac{\tau w(1+\mu)}{z}\right]^{1-\sigma}}{P^{* \sigma} Q^{*}\left[\frac{\sigma}{\sigma-1} \frac{\tau w(1+\mu)}{z}\right]^{1-\sigma}+P^{\sigma} Q\left[\frac{\sigma}{\sigma-1} \frac{w(1+\alpha \mu)}{z}\right]^{1-\sigma}}
$$

Finally, we show that export sales $\hat{p}^{*} \hat{q}^{*}$ and export intensity $\frac{\hat{p}^{*} \hat{q}^{*}}{\hat{p} \hat{q}+\hat{p}^{*} \hat{q}^{*}}$ increase as $\mu$ decreases:

$$
\begin{gathered}
\frac{\partial \hat{p}^{*} \hat{q}^{*}}{\partial \mu}=(1-\sigma)(1+\mu)^{-\sigma} P^{* \sigma} Q^{*}\left[\frac{w \tau}{z} \frac{\sigma}{\sigma-1}\right]^{1-\sigma}<0 \text { if } \sigma>1 \\
\frac{\partial \hat{p} \hat{q}}{\partial \mu}=\alpha(1-\sigma)(1+\alpha \mu)^{-\sigma} P^{\sigma} Q\left[\frac{w}{z} \frac{\sigma}{\sigma-1}\right]^{1-\sigma}<0 \text { if } \sigma>1 \\
\frac{\partial\left(\frac{\hat{p}^{*} \hat{q}^{*}}{\hat{p}^{*} \hat{q}^{*}+\hat{p} \hat{q}}\right)}{\partial \mu}=\frac{1}{\left(\hat{p}^{*} \hat{q}^{*}+\hat{p} \hat{q}\right)^{2}}\left(\frac{\partial \hat{p}^{*} \hat{q}^{*}}{\partial \mu} \hat{p} \hat{q}+\frac{\partial \hat{p}^{*} \hat{q}^{*}}{\partial \mu} \hat{p}^{*} \hat{q}^{*}-\frac{\partial \hat{p} \hat{q}}{\partial \mu} \hat{p}^{*} \hat{q}^{*}-\frac{\partial \hat{p}^{*} \hat{q}^{*}}{\partial \mu} \hat{p}^{*} \hat{q}^{*}\right)<0 \\
\Leftrightarrow \frac{\partial \hat{p}^{*} \hat{q}^{*}}{\partial \mu} \hat{p} \hat{q}-\frac{\partial \hat{p} \hat{q}}{\partial \mu} \hat{p}^{*} \hat{q}^{*}<0 \\
\Leftrightarrow(1-\sigma)(1-\alpha)<0 \text { if } \sigma>1
\end{gathered}
$$

where the last line follows from replacing the expressions for derivatives obtained above. This completes the proof of the proposition. 


\section{A.2. Domestic Sales Growth Dynamics}

In this section we study the robustness of the dynamics of domestic sales upon export entry documented in the paper. Specifically, we provide further empirical support for the fact that domestic sales decrease upon entry to the export market.

We begin by computing the average growth rate of domestic sales (in logs) among the sample of plants that transition from not exporting to exporting, and which export for at least four consecutive years. ${ }^{54}$ In Figure A.1, we plot the dynamics of this measure along with its two standard deviation bands. The figure shows that, not only does domestic sales growth fall upon entry to the export market, but it is also negative on average with 95 percent confidence. After the first year in the export market, domestic sales have positive growth on average, yet not with 95 percent confidence.

Given that only a subset of all exporters exports for at least four consecutive years. Therefore, we now examine the extent to which the previous finding is also observed among all firms that export, regardless of the length of their export spell. To do so, we follow the approach of Bernard and Jensen, 1999. We divide plants into groups based on their export status in periods $t$ and $t+1$, discarding plants which are not observed in both periods. Firms that do not export in $t$ but export in $t+1$ are classified as starters. Firms that export in period $t$ but do not do so in period $t+1$ are classified as stoppers. Finally, those that export in both periods are classified as continuing exporters, while those that do not export in either period are referred to as continuing non-exporters. To estimate the extent to which the domestic sales growth of starters between $t$ and $t+1$ is lower than that of the other groups, we regress the log-growth of domestic sales on dummies corresponding to each of the groups (choosing continuing non-exporters as the excluded group). The results are reported in Table A.1: the first column reports the regression estimates without controlling for other covariates, while the second column controls for industry-year fixed effects, region fixed effects, and the log of total sales.

\footnotetext{
${ }^{54}$ We exclude plants that export upon birth.
} 
Figure A.1: Domestic sales growth

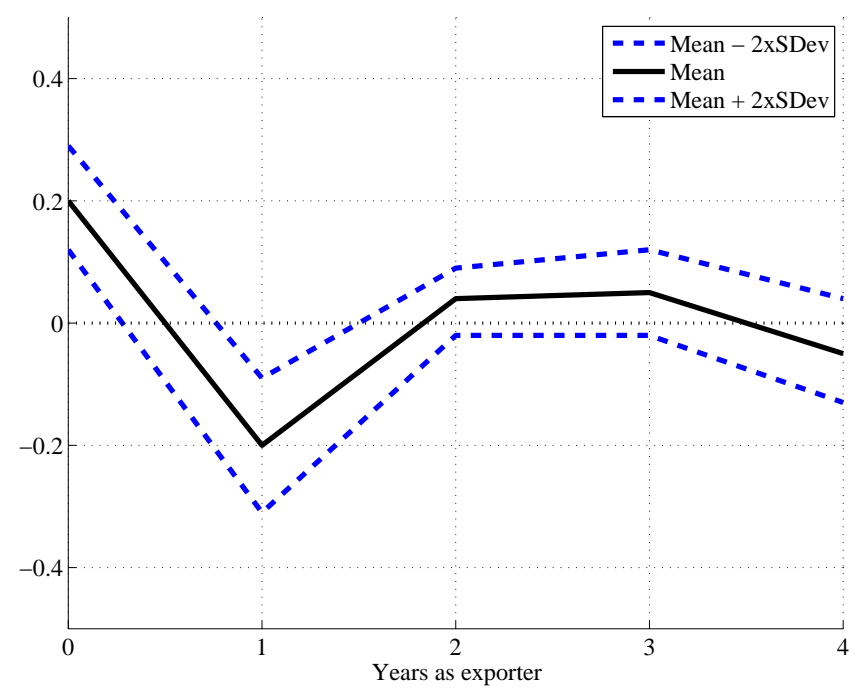

In both specifications, we find that starters grow at a lower rate than plants in any of the other groups. In particular, they have 11 percentage point lower growth rate of domestic sales than the firms that continue being non-exporters. These effects are statistically significant at a 1 percent level. Controlling for a measure of plant size, as well as for industry-year and region fixed effects, export entrants grow at 8 percent slower than continuing non-exporters, 15 percent slower than continuing exporters, and 22 percent slower than stoppers.

Table A.1: Regression of domestic sales growth (log) on export transitions

\begin{tabular}{ccc}
\hline \hline & No controls & With controls \\
\hline Starter & $-0.11^{* * *}$ & $-0.08^{* * *}$ \\
Stopper & $0.11^{* * *}$ & $0.14^{* * *}$ \\
Continuing exporter & $0.03^{* * *}$ & $0.07^{* * *}$ \\
\hline Total sales (log) & No & Yes \\
Industry-year fixed effects & No & Yes \\
Region fixed effects & No & Yes \\
\hline Observations & 46151 & 46151 \\
R-squared & 0.0029 & 0.0236 \\
\hline \hline
\end{tabular}

\section{References}

Ahn, J., "A Theory of Domestic and International Trade Finance," IMF Working Paper No. 11/262, 2011. 
Alessandria, G. And H. Choi, "Establishment Heterogeneity, Exporter Dynamics, and the Effects of Trade Liberalization," Journal of International Economics 94 (2014), 207223.

Amiti, M. And D. Weinstein, "Exports and Financial Shocks," The Quarterly Journal of Economics 126 (2011), 1841-1877.

Anderson, J. And E. VAn Wincoop, "Trade Costs," Journal of Economic Literature 42 (2004), 691-751.

Antras, P. And A. Costinot, "Intermediated Trade," The Quarterly Journal of Economics 126 (2011), 1319-1374.

Antras, P. And C. F. Foley, "Poultry in Motion: A Study of International Trade Finance Practices," NBER Working Paper No. 17091, 2011.

Arellano, C., Y. Bai And J. Zhang, "Firm Dynamics and Financial Development," Journal of Monetary Economics 59 (October 2012), 533-549.

Arkolakis, C., "A Unified Theory of Firm Selection and Growth," NBER Working Papers $17553,2011$.

Bai, X., K. Krishna And H. Ma, "How You Export Matters: Export Mode, Learning, and Productivity in China," Working Paper, 2013.

Bellone, F., P. Musso, L. Nesta And S. Schiavo, "Financial Constraints and Firm Export Behaviour," The World Economy 33 (March 2010), 347-373.

Berman, N. And J. Hericourt, "Financial factors and the margins of trade: Evidence from cross-country firm-level data," Journal of Development Economics 93 (2010), 206217.

Bernard, A. B. And J. B. Jensen, "Exceptional Exporter Performance: Cause, Effect, or Both?," Journal of International Economics 47 (1999), 1-25. 
Blum, B. S., S. Claro And I. J. Horstmann, "Occasional and perennial exporters," Journal of International Economics 90 (2013), 65-74.

Blundell, R., C. Meghir and P. Neves, "Labor Supply and Intertemporal Substitution," Journal of Econometrics 59 (1993), 137-160.

Brooks, W. And A. Dovis, "Trade Liberalization with Endogenous Borrowing Constraints," Working Paper. University of Minnesota, 2011.

Caggese, A. And V. Cunat, "Financing Constraints, Firm Dynamics, Export Decisions, and Aggregate Productivity," Review of Economic Dynamics 16 (January 2013), 177-193.

Chaney, T., "Liquidity Constrained Exporters," NBER Working Papers 19170, 2013.

Clementi, G. L. And H. A. Hopenhayn, "A Theory of Financing Constraints and Firm Dynamics," Quarterly Journal of Economics 121 (2006), 229-265.

Cooley, T. And V. Quadrini, "Financial Markets and Firm Dynamics," American Economic Review 91 (2001).

Das, S., M. J. Roberts and J. R. Tybout, "Market Entry Costs, Producer Heterogeneity, and Export Dynamics," Econometrica 75 (2007), 837-873.

Duankov, S., C. Freund and C. S. Pham, "Trading on Time," The Review of Economics and Statistics 92 (2010), 166-173.

Eaton, J., M. Eslava, D. Jinkins, C. J. Krizan and J. Tybout, "A Search and Learning Model of Export Dynamics," Working Paper, 2014.

Eaton, J., M. Eslava, M. Kugler and J. Tybout, "Export Dynamics in Colombia: Transactions Level Evidence," Working Paper, 2008.

Eaton, J., S. Kortum and F. Kramarz, "An Anatomy of International Trade: Evidence from French Firms," Econometrica 79 (2011), 1435-1498. 
Egger, P. And M. Kesina, "Financial Constraints and Exports: Evidence from Chinese Firms," CESifo Economic Studies 59 (2013), 676-706.

Feenstra, R. C., M. Yu And Z. Li, "Exports and Credit Constraints under Incomplete Information: Theory and Evidence from China," The Review of Economics and Statistics 96 (October 2014), 729-744.

Greenaway, D., A. Guariglia and R. Kneller, "Financial factors and exporting decisions," Journal of International Economics 73 (2007), 377-395.

Gross, T. And S. Verani, "Financing Constraints, Firm Dynamics, and International Trade," FRB, Finance and Economics Discussion Series, 2013.

Guvenen, F., "Reconciling conflicting evidence on the elasticity of intertemporal substitution: A macroeconomic perspective," Journal of Monetary Economics 53 (2006), 14511472.

Hummels, D. L. And G. Schaur, "Time as a Trade Barrier," American Economic Review $103(2013)$.

JaeBin, A., A. K. Krandelwal and S.-J. Wei, "The Role of Intermediaries in Facilitating Trade," Journal of International Economics 84 (2011), 73-85.

Leibovici, F., "Financial Development and International Trade," mimeo, 2014.

Leibovici, F. And M. E. Waugh, "International Trade and Intertemporal Substitution," NBER Working Paper No. 20498, 2014.

Manova, K., "Credit Constraints, Equity Market,Liberalizations and International Trade," Journal of International Economics 76 (2008), 33-47.

—, "Credit Constraints, Heterogeneous Firms, and International Trade," Review of Economic Studies 80 (April 2013), 711-744. 
Melitz, M. J., "The Impact of Trade on Intra-Industry Reallocations and Aggregate Industry Productivity," Econometrica 71 (November 2003), 1695-1725.

Minetti, R. And S. Zhu, "Credit Constraints and Firm Export: Microeconomic Evidence from Italy," Journal of International Economics 83 (November 2011), 1695-1725.

Moll, B., "Productivity Losses from Financial Frictions: Can Self-Financing Undo Capital Misallocation?," American Economic Review 104 (2014), 3186-3221.

Muuls, M., "Exporters and credit constraints. A firm-level approach," Working Paper Research 139, National Bank of Belgium, 2008.

Roberts, M. J. And J. R. Tybout, "The Decision to Export in Colombia: An Empirical Model of Entry with Sunk Costs," American Economic Review 87 (1997), 545-564.

Ruhl, K. J., "The International Elasticity Puzzle," NYU Stern School of Business, 2008.

Ruhl, K. J. And J. L. Willis, "New Exporter Dynamics," NYU Stern School of Business, 2014. 